\title{
The Symbolic Self in Evolutionary Context
}

\author{
Constantine Sedikides \\ Department of Psychology \\ University of North Carolina, Chapel Hill
}

John J. Skowronski

Department of Psychology

Ohio State University, Newark

\begin{abstract}
We propose that the capacity for a symbolic self (a flexible and multifaceted cognitive representation of an organism's own attributes) in humans is a product of evolution. In pursuing this argument, we note that some primates possess rudimentary elements Of a self (an objectified self) and that the symbolic self (a) is a trait that is widely shared among humans, (b) serves adaptive functions, and (c) could have evolved in response to environmental pressures, with ecological and social pressures being of particular relevance. We suggest that these two environmental pressures caused the symbolic self to emerge in the Pleistocene epoch as an adaptation for Homo erectus, and we review the possible functions served by such an adaptation.
\end{abstract}

The notion of biological evolution, first articulated by Darwin $(1859,1871)$ and refined by later theorists (Gould, 1982; Huxley, 1957; Rensch, 1959), has dramatically affected the way people think about the natural world, themselves, other people, and society. The field of psychology certainly reflects this influence as ideas borrowed from evolution are prominent in several major theoretical formulations (CampbelI, 1975; Cavalli-Sforza \& Feldman, 198 1; James, 1898; Lorenz, 1963; E. 0. Wilson, 1975). In fact, incorporation of the principles of evolution into the social sciences has led to the emergence of one of the most intriguing recent developments in psychology: the area of evolutionary psychology (Barkow, Cosmides, \& Tooby, 1992; Buss, 1991, 1995; DeKay \& Buss, 1992; Kenrick, 1994; Shettleworth, 1993; Symons, 1992; Tooby \& Cosmides, 1990a).

Evolutionary psychologists capitalize on the most powerful concept in the theory of evolution: natural selection. According to this concept, some heritable traits (or adaptations) promote reproductive success in a particular set of environmental circumstances. Hence, these adaptations become dispersed throughout a population. In their application of this concept to the understanding of thought, emotion, and behavior, evolutionary psychologists focus on three overarching issues: (a) the temporal origins of adaptations, (b) the ecologically

\section{We are grateful to Marilynn B. Brewer and the anonymous} review-

ers for their thoughtful and constructive suggestions.

Requests for reprints should be sent to Constantine Sedikides, Department of Psychology, Davie Hall, CB \#3270, University of North Carolina, Chapel Hill, NC 27599-3270. E-mail: dionysus@unc.edu. important problems that selected for these adaptations, and (c) the functions that these adaptations serve (DeKay \& Buss, 1992; Symons, 1992).

Evolutionary psychologists are particularly attentive to the specifics of the natural history and behavior of the species under consideration. This focus on specifics occurs because evolutionary psychologists generally assume that the adaptations that are selected through evolution are highly modular and domain-specific (Buss, 1991, 1995; Symons, 1992). In short, adaptations are not dispersed willy-nilly; instead, specific adaptations spread in response to specific environmental problems. This specificity causes evolutionary psychologists to be particularly sensitive to context-be it historical context, ontogenetic context, or immediate situational inputs (Buss, 1995).

Furthermore, in their analyses, evolutionary psychologists often make interspecies comparisons. Several different kinds of interspecies comparisons can be useful. For example, information about the selection of different mental and behavioral traits may come from comparison of closely related species that face divergent (environmentally imposed) cognitive demands. Alternatively, evolutionary psychologists may look for mental or behavioral similarity in distantly related species that face similar environmental demands (Shettleworth, 1993). More often than not, nonhuman species are compared with one another, rather than being explicitly or implicitly compared with humans (Shettleworth, 1993, p. 180). Nonetheless, because humans are viewed as a part of the evolutionary continuum, humans are not excluded from these analyses.

It is no surprise, then, that evolutionary psychologists have frequently used natural selection to explain 
many human traits and behaviors. Examples of areas in which such analyses have been conducted include mate age preferences (Kenrick \& Keefe, 1992), relationship commitment (Kenrick, Groth, Trost, \& Sadalla, 1993; Oliver \& Sedikides, 1992), sexual fantasy (Ellis \& Symons, 1990), sexual jealousy (Buss, Larsen, Westen, \& Semmelroth, 1992), specific memory abilities (i.e., women having better spatial-location memory and men having better spatial -rotation ability; Silverman \& Eals, 1992), sexual attractiveness (Gangestad \& Simpson, 1990; Symons, 1992), mating strategies (Buss, 1989, 1994; Buss \& Schmitt, 1993), anxiety (Buss, 1990b), aggression (Smuts, 1991), repression and other psychodynamic mechanisms (Nesse, 1990; Nesse \& Lloyd, 1992), gossip and social stratification (Barkow, 1992), aesthetic preferences (S. Kaplan, 1992), and adaptations for solving socioeconomic exchange problems (Tooby \& Cosmides, 1992).

\section{Overview}

Despite the substantial list of characteristics that have been subjected to evolutionary analyses, there is one important topic that has largely escaped the study of evolutionary psychologists: what we are calling the symbolic $s e \sim f$ Our central thesis in this article is that the symbolic self is an adaptation. That is, we argue that the symbolic self is a broad-based capacity that was selected and distributed in the human population because of its high adaptive significance.

In our attempt to support this thesis, we address in this article the important issues that are the focus of evolutionary psychologists: (a) the possible temporal origins of the symbolic self, (b) the ecologically important problems that potentially spurred the evolution of the symbolic self, and (c) the likely evolutionary functions of the symbolic self. We also use cross-species comparisons to argue our case. Finally, because the evolution of complex cognitive capabilities was a necessary (but not sufficient) precursor to the evolution of a symbolic self, in our attempt to specify the origins of the symbolic self we also address the evolution of these cognitive capabilities.

However, before we discuss these issues, we first attend to definitional and descriptive matters. We distinguish among three different aspects of self: subjective self-awareness, objective self-awareness, and symbolic self-awareness. We argue that subjective self-awareness is an attribute of all living organisms, objective self-awareness is an attribute of only a handful of primate species (i.e., chimpanzees, orangutans, and humans), and symbolic self-awareness is an attribute unique to humans. Further, we argue that although objective self-awareness may lead to the formation of a crude self-concept (the objectified see, symbolic self-awareness leads to the formation of a highly refined self-concept (the symbolic see. In the course of de- scribing the symbolic self, we review briefly the literature highlighting the richness of content and the complexity of structure of the symbolic self.

After these initial definitional and descriptive issues are dispensed with, we use the core ideas of evolutionary psychology to build our case for the evolutionary origins of the symbolic self. First, we describe the remarkable diversity of the functions of the symbolic self-namely, its powerful effects on cognitive, affective, motivational, and behavioral processes. Second, we describe a timeline for human evolution and attempt to place the evolution of the symbolic self in this temporal context. Third, we use this timeline to discuss the various selection pressures that we believe are responsible for the evolution of the symbolic self and focus on the functions that the symbolic self served in relation to these pressures. In the course of these arguments, we also discuss the evolution of advanced cognitive capabilities in humans, a necessary (but not sufficient) condition for the evolution of a symbolic self. Although the discussion of the selection

pressures is speculative, we support the existence of such pressures by citing recent theory and data whenever possible. Our final step in supporting our thesis is to compare the self in humans (i.e., symbolic self) to the self in nonhumans (i.e., objectified self) and consider whether the human symbolic self could have evolved from the objectified self.

\section{Definitional Matters: Subjective, Objective, and Symbolic Self-Awareness}

To begin our exposition, we distinguish among three relevant aspects of self: subjective self-awareness, objective self-awareness, and symbolic self- awareness.' This discussion builds on distinctions between subjective and objective self-awareness drawn by Duval and Wicklund (1972; Wicklund, 1975) and by Lewis (1992). This discussion also builds on Mitchell's (1994, pp. 98-99) summary of aspects of the self-concept in humans and nonhumans.

\section{Subjective Self-Awareness}

Subjective self-awareness refers to the organism's cognitive capacity to distinguish crudely between the

'In his thinking about the self, James (1890/1950) drew a distinction between the pure ego, or 1, and the empirical self, or Me. Allport (1943) rephrased the distinction in terms of the self as subject of knowledge and self as object (of knowledge. The self as subject of knowledge refers to the ability to initiate action (e.g., perceiving, remembering, planning, behaving). On the other hand, the self as object of knowledge refers to being able to recognize oneself as an object of one's own perception or cognition. For the purposes of this article, we assume that subjective selfawareness manifests the operation of the self as subject of knowledge, whereas objective and symbolic selfawareness refer to the self as object of knowledge. 


\section{SEDIKIDES \& SKOWRONSKI}

organism (the self) on the one hand and the physical or social environment on the other. This self-other distinction allows the organism to (a) engage in some form of self-regulation (a process where systemic parts coordinate the action of each other; Von Bertalanffy, 1967) and (b) perceive the environment, interpret it, operate on it, and change it through self-initiated movements. It is worth noting that subjective self-awareness does not imply that a cognitive representation of the organism's attributes is constructed and stored in memory; instead, it merely implies a crude differentiation between the organism and the environment. This differentiation makes survival possible and, along with selfregulation and response to environmental stimuli, is implicit or nonconscious (Damasio, 1994).

There are several millions of species on Earth, most of which are plants, microorganisms, and insects (Gallup, 1985). In agreement with Lewis (1992), we have no problem in accepting that all living species possess subjective self-awareness. That is, all living species self-regulate and respond to environmental stimulation. However, the ways in which species interact with the environment vary immensely. For example, many animals process relatively complex visual and auditory stimuli, cognitively represent their social and nonsocial environment, count, remember, categorize, communicate both with each other and with predators, use tools, and develop resourceful problem-solving strategies (Gallistel, 1989; Ristau, 1991; Snowdon, 1991). Nevertheless, these cognitive abilities do not presuppose a cognitive representation of self and can be carried out in the absence of such a representation.

\section{Objective Self-Awareness}

Objective self-awareness is defined as the organism's cognitive capacity to "become the object of its own attention" (Gallup, 1992, p. 117), to be aware of its "own state of mind" (Cheney \& Seyfarth, 1992, p. 240), and "to know it knows, to remember it remembers" (Lewis, 1992, p. 124). Objective self-awareness implies the presence of a primitive cognitive representation of the self, which we term the objectified self. Furthermore, objective self-awareness allows for selfreferential behavior; that is, it allows the use of one's own knowledge to model the knowledge of other organisms. This reflective capacity occurs at a substantially more explicit or conscious level than subjective self-awareness.

The capacity for objective self-awareness presupposes and subsumes the capacity for subjective selfawareness. Objective self-awareness can, in varying degrees, induce, terminate, alter, and generally control subjective self-awareness. This does not necessarily imply that objective self-awareness is always in control of subjective self-awareness. Instead, objective self- awareness can, if necessary, focus on and regulate aspects of subjective self-awareness (Bargh, 1984; Damasio, 1994; Lewis, 1992).

Current evidence suggests that most of the great apes (in particular, chimpanzees, orangutans, and humanS2) possess the capacity for objective self-awareness and, consequently, an objectified self.' For example, chimpanzees manifest the ability for self-recognition, which can arguably be taken as an indicator of the organism's ability to become the object of its own attention. Data supporting this point have been provided by Gallup $(1970,1977)$. Gallup applied paint to a chimpanzee's brow-ridge or ear when the chimpanzees were under anesthesia. Chimpanzees (and also orangutans; see Suarez \& Gallup, 1981) recognized themselves in a mirror and removed the spots of paint, behavior that seemingly requires knowledge that the image in the mirror is not external, but is the self. Similarly, SavageRumbaugh (1986) reported that chimpanzees recognized themselves at television monitors and would even position their bodies properly in order to enhance the

${ }^{2}$ Current evidence excludes gorillas from this group. The failure to obtain conclusive evidence for selfrecognition abilities in most gorillas (Ledbetter \& Basen, 1982; Suarez \& Gallup, 1981) is surprising, especially in view of the evidence suggesting that chimpanzees, orangutans, gorillas, and humans share a common ancestor (Yunis \& Prakash, 1982). One reason may be that gorillas evidently split from the ape-human stem approximately 8.0 to 9.9 million years ago, whereas chimpanzees (and likely orangutans) split 6.3 to 7.7 million years ago (Sibley \& Ahlquist, 1984). The ability for selfrecognition may have been refined during the intervening period. Alternatively, Povinelli (1993) proposed that gorillas have suffered a secondary loss of the ability for selfrecognition. More pecifically, because of ecological pressures that favored early physical maturation, sensorimotor cognitive pathways may have interfered with the growth of brain structures underlying the capacity for selfrecognition (i.e., early locomotion may have been acquired at the expense of objective selfawareness). Povinelli (1993) further pointed out that powerful ecological inputs, especially during early ontogeny, ought to be able to lead to the reemergence of the "turned off' selfrecognition capacity. In that sense, it is not surprising that Koko, a home-reared gorilla exhibits the capacity for selfrecognition (Patterson \& Linden, 1981). Finally, another reason for the relative failure of gorillas to show mirror-mediated selfrecognition is the social environment of testing. Although chimpanzees require a restrictive social environment to focus attention on the mirror, gorillas require a supportive and rich social environment. Thus, gorillas may have been tested in inappropriate laboratory environments (Boccia, 1994; Swartz \& Evans, 1994).

${ }^{3}$ Bonobos are also included among the great apes. However, existing evidence pointing to bonobos' selfrecognition abilities is only preliminary (Hyatt \& Hopkins, 1994). In a similar vein, evidence for the selfrecognition capacity of another likely candidate species, dolphins, is also preliminary (Marino, Reiss, \& Gallup, 1994; Marten \& Psarakos, 1994).

${ }^{4}$ For alternative views, see Eglash and Snowdon (1983) and M. W. Fox (1982). For criticism of the mirror selfrecognition task, see Miles (1994) and Mitchell (1993). For rebuttals to such criticism, see Gallup (1994) and Povinelli (1994). Finally, for a case of equivocal evidence for the mirror selfrecognition task in chimpanzees, see Swartz and Evans (1994). 


\section{THE SYMBOLIC SELF}

observational clarity of their facial expressions, bodily postures, and methods of eating.

Gallup (1983, 1985; Gallup\& Suarez, 1986) reasoned that, if the presence of objective self-awareness involves necessarily the capacity to use the self referentially, then chimpanzees, orangutans, and humans (beginning at the age of 15 to 24 months) ought to be able to (a) reflect on their own knowledge state in a certain situation and reason inferentially about another organism's knowledge state in the same or similar situation (see also D. Premack \& Woodruff, 1978), (b) anticipate what other organisms might do (i.e., by attributing intentions to other organisms), and (c) influence other organisms (e.g., by intervening in their behavior). Organisms without objective selfawareness should not exhibit such capabilities.

Empirical evidence has been consistent with Gallup's (1983, 1985; Gallup \& Saurez, 1986) theorizing. Chimpanzees are apparently capable of understanding the relaflon between perceiving and the resulting cognitive state of knowing, but rhesus macaques are not (Povinelli, Nelson, \& Boysen, 1992b). Likewise, chimpanzees are capable of understanding cause-effect relations, but capuchin monkeys are not (Visalberghi \& Trinca, 1989). Furthermore, chimpanzees are capable of role taking, whereas rhesus macaques are not (Povinelli, Nelson, \& Boysen, 1992a; Povinelli, Parks, \& Novak, 1992). Most important, behaviors such as the attribution of knowledge states in others (D. Premack \& A. G. Premack, 1983; see also Seyfarth \& Cheney, 1989), responsibility taking (Goodall, 1986; D. Premack \& Woodruff, 1978), concealment (Savage-Rumbaugh $\&$ McDonald, 1988), distraction and lying (Menzel, 197 1; D. Premack \& Woodruff, 1978), creation of a social image (de Waal, 1982), and intentional intraspecies deception (de Waal, 1982, 1986) have been documented conclusively in chimpanzees, orangutans, and humans.' Species that do not show evidence for self-recognition also do not demonstrate compelling evidence of being capable of performing the aforementioned behaviors (Gallup, 1985, 1992; Povinelli, 1993). Furthermore, development of mirror-mediated self-recognition in nonhuman species coincides with the emergence of many of the aforementioned behaviors (Povinelli, Rulf, \& Bierschwale, 1993).6

\section{Symbolic Self-Awareness}

The arguments that we offer for the evolution of the self apply largely to the third aspect of self: symbolic

self-awareness. Symbolic self-awareness refers to the unique capacity of the adult human organism to:

1. Form an abstract cognitive representation of itself through language, a representation we term the symbolic self.'
2. Communicate the symbolic self to other organisms and negotiate the content of the symbolic self with other organisms in an effort to establish personal and social relationships.

3. Set social or achievement goals that are prompted by the symbolic self far into the future.

4. Perform goal-guided behaviors.

5. Evaluate the outcome of these behaviors (i.e., judge whether the behaviors have fulfilled the relevant goals).

6. Link the behavioral outcome to feelings toward the symbolic self (e.g., high self-esteem or pride when goals are met, and shame or embarrassment when goals are not met).

7. Defend the symbolic self against threatening events and ideas through several strategies, such as avoidance of negative feedback, derogation of negative evaluators, rejection of negative feedback, and even self-deception.

The symbolic self presupposes the objectified self and relies on the objectified self for the development, consolidation, and refinement of the symbolic self's content, structure, and functions.

In sum, the symbolic self refers to both the languagebased and abstract representation of one own's attributes and the use of this representation for effective functioning in affective, motivational, and behavioral domains. To further clarify and specify our ideas about the symbolic self, we highlight briefly its content and structure. Then, we begin our evolutionary argument by describing in more detail the functions served by the symbolic self.

\section{Content and Structure of the Symbolic Self}

Research on the content of the symbolic self has accentuated its diversity, and for good reason. The symbolic self as a corpus of knowledge contains infor-

5 However, for arguments favoring the occasional presence of intentional intraspecies deception in other nonhuman species besides chimpanzees and orangutans, see Byrne and Whiten (1988; Whiten \& Byrne, 1988) and Mitchell and Thompson (1986).

6 Although not yet definitive, some evidence (LeDoux, 1989; Stuss, 199 1; Weiskrantz, 1986) points to certain regions of the brain being responsible for the emergence of the objectified self. This evidence suggests that subjective selfawareness is located in the limbic system, whereas objective selfawareness is located in the frontal lobes.

7 Note that the term symbolic self is essentially equivalent to the term self-concept. We opted to use symbolic self here because it corresponds better to the capacity we labeled symbolic self-awareness and because we wanted to polarize the distinction between the rich selfconcept that is characteristic of humans (i.e., symbolic self) and the relatively crude selfconcept that is characteristic of higher order primates (i.e., objectified self). 


\section{SEMMES \& SK0WRONSK1}

mation about activities, life events, physical attributes, demographic characteristics, personality qualities, feelings, thoughts, goals, values, standards, rules for behavioral regulation, significant relationships with individuals or groups, and possessions (Belk, 1988; Markus, 1983). The content of the symbolic self is dynamic. It varies across cultures (Markus \& Kitayama, 1991; Triandis, 1989) and is altered as a function of life events (Deutsch, Ruble, Fleming, Brooks-Gunn, \& Stangor, 1988) and social environments (e.g., home vs. school; McGuire, MeGuire, \& Cheever, 1986).

The structure of the symbolic self is as polymorphous as its content. The symbolic self has been conceptualized as a collection of propositional networks (Bower \& Gilligan, 1979), a schema (Markus, 1977), a prototype (Kuiper, 1981), a polyphonic novel (Hermans, 1996), and as a location in multidimensional trait space (Breckler, Pratkanis, \& McCann, 199 1). Furthermore, the symbolic self has been structurally subdivided in several ways. Researchers have proposed and empirically documented the private and public selves (Baumeister, 1986); the actual, ought, and ideal selves (Higgins, 1987); and the possible self (Markus \& Nurius, 1986). Although structural polymorphism within a single individual across time would challenge the utility of the symbolic self as a scientific construct, both nomothetic and idiographic research suggests that the structure of the symbolic self is relatively stable, persists across time, and is transformed predictably as a function of development (Damon \& Hart, 1986; Monge, 1975; Mortimer \& Lorence, $1981)$.

\section{Psychological Functions of the Symbolic Self}

One of the main issues addressed by evolutionary psychologists concerns the function of adaptations. The symbolic self serves multiple functions, namely, the regulation of cognitive, affective, motivational, and behavioral processes in a variety of intrapersonal and interpersonal domains (Banaji \& Prentice, 1994; Markus \& Wurf, 1987) across the life span (Breytspraak, 1984; Damon, 1983; Lewis, 1990). To illustrate its importance and adaptiveness, we review a sample of the literature documenting in more detail the psychological functions of the symbolic self.'

${ }_{8}$ Obviously, the symbolic self can lead to negative consequences, such as feelings of low selfesteem and selfalienation, concern over mortality, and selfrejection (e.g., suicide; Baumeister, 1991; Rosenberg, 1988). For reasons of brevity and focus, we do not devote extensive space to reasons of brevity issue. However, this point is not threatening to our evolutionary argument. As in the case of sickle-cell anemia, some traits that increase the overall fitness of a species in a particular environment can still have negative consequences in other environments or for specific individuals.
Before proceeding, however, a few clarifications are in order. We certainly do not wish to maintain that any trait that is widespread in a population is necessarily adaptive, a logical error known as the naturalistic fallacy. Indeed, though natural selection suggests that widely held traits in a population may, at one time, have facilitated reproductive survival in a particular environment, the fact that a trait is currently widely held does not necessarily imply that it is (or was) adaptive. Clearly, not all widely held traits are adaptive; some traits appear to have no bearing on reproductive fitness.

A somewhat more insidious problem is that a trait may have originally evolved to serve a different function than the one it currently serves. That is, the environmental pressures that led to the initial spread of a trait may no longer be important, but the trait itself may continue to be maintained because it is responsive to alternative environmental pressures. Hence, we acknowledge that the symbolic self may have originally had different functions than those currently served.

We note at the outset that we are aware of these problems. Thus, we do not wish to be misconstrued as advocating circular and logically flawed positions-such as the notion that because the symbolic self is adaptive at present, human cognition must have evolved so that the symbolic self was adaptive. Nonetheless, the fact that a trait is widely held in a population and is currently adaptive constitutes a legitimate basis for exploring the possibility that the trait evolved in response to environmental pressures. Furthermore, it is undeniable that the symbolic self is a widespread human trait, and we argue that the symbolic self serves adaptive functions. In subsequent sections of this article, we attempt to support the idea that the current adaptive functions were, indeed, the functions selected by evolution.

Symbolic self and cognitive processes. The symbolic self plays a prominent role in human information processing. People manifest a nonconscious processing sensitivity for self-reIevant stimuli (Bargh, 1982), process self-descriptive information faster than self-irrelevant information (Markus, 1977), and remember self-relevant information better than other-relevant information (Skowronski, Betz, Thompson, \& Shannon, 1991). Further, people remember self-referentially encoded material better than material encoded with reference to others (Rogers, Kuiper, \& Kirker, 1977) and remember material generated by the self better than material generated by someone else (Greenwald \& Banaffi, 1989).

The symbolic self also affects social perception. People perceive and judge others on self-relevant dimensions (Markus, Smith, \& Moreland, 1985). Moreover, when these dimensions are central to the symbolic self, people tend to (a) draw a large number of inferences about others, (b) draw extreme inferences about 
others (Sedikides \& Skowronski, 1993), (c) process information in large chunks, and (d) process the information deeply (Markus et al., 1985). Finally, the symbolic self plays an important role in determining friend and romantic partner choice (Cantor, Mackie, \& Lord, 1984; Snyder, Gangestad, \& Simpson, 1983).

Symbolic self and affect. The structure of the symbolic self is associated with affect. One example comes from the relation between patterns of self-beliefs and affect. Discrepancies between the actual and the ideal self can lead to dejection-related affect, whereas discrepancies between the actual and the ought self can lead to agitation-related affect (Higgins, 1987). Another example comes from the relation between the structural complexity of the symbolic self and affect. Individuals who have structurally complex selves are less vulnerable to stress and depression than those who have less complex selves (Linville, 1987).

In the interest of maintaining a positively balanced affective state, people bias their processing of self-relevant information to maintain (S warm, 1990) or enhance (Brown \& Dutton, 1995; Sedikides, 1993; Sedikides \& Strube, in press) the symbolic self. For example, people perceive positive affect terms as being more applicable to the self than negative affect terms, and this tendency is accentuated when people think about experiencing affect in a future context (Staats \& Skowronski, 1992). People judge themselves as being above average on a wide array of attributes (Alicke, 1985), and they define their attributes in an idiosyncratic and self-serving manner (Dunning, 1993). People take credit for their successes but deny responsibility for their failures (Bradley, 1978). They sustain such beliefs by generating and evaluating causal theories that are consistent with these beliefs (Kunda, 1990). They make downward as opposed to upward comparisons, particularly after experiencing failure or negative affect (Wills, 1981), and avoid comparing themselves directly with friends on personally important attributes (Tesser, 1988). Furthermore, people remember information favorable to the symbolic self better and process it faster than information unfavorable to the symbolic self (Skowronski et al., 1991). Such biased perceptions of the symbolic self generally serve to maintain positive evaluations of, or feelings for, the symbolic self. This positive self-esteem is associated with successful personal adjustment, better psychological health (e.g., lower depression, anxiety, and loneliness), improved coping, and enhanced physical health (Kahle, Kulka, \& Klingel, 1980; Taylor \& Brown, 1988; Whitley, 1983; but see Baumeister, Smart, \& Boden, 1996).

Symbolic self, motivation, and behavior. The symbolic self leads to the setting of goals that are congruent with the content of the symbolic self. Examples of this principle can be derived from such diverse domains as implementation of life tasks (Cantor, Markus, Niedenthal, \& Nurius, 1986), therapeutic outcomes (Meichenbaum, 1977), orientations toward occupational and educational achievement (Ruvolo \& Markus, 1992; Wicklund \& Gollwitzer, 1982), and delinquency (Oyserman \& Markus, 1990).

Likewise, the symbolic self leads to behavior that is consistent with the content of the symbolic self. For example, inducing participants to believe that they are neat influences them to throw less garbage on the floor (Miller, Brickman \& Bolen, 1975); inducing participants to think of themselves as charitable persons results in increased donation behavior (Kraut, 1973); asking participants to imagine having cable television results in increased subscriptions (Gregory, Cialdini, \& Carpenter 1982); and inducing participants to think of themselves as honest enhances the likelihood of returning a pencil (Shotland \& Berger, 1970). More generally, the symbolic self has been linked to numerous behaviors, such as deviance (H. B. Kaplan, 1975), involvement in intimate relationships (Cupach \& Metts, 1994), and strategic presentation of selected content attributes for the sake of social or professional gains (Schlenker, 1980).

\section{The Symbolic Self as an Adaptation: \\ When, How, and Why Was the Symbolic Self Selected?}

The research reviewed so far suggests that the symbolic self plays a crucial role in human thinking, feeling, and behaving. More important, this role is often to enhance functioning. That is, the symbolic self often participates in processes that result in efficient cognition, effective behavior, better adjustment, and improved health. These critical and positive consequences suggest the possibility that the symbolic self is an adaptation. We examine this possibility as an evolutionary psychologist might-by exploring the possible temporal origins of this adaptation, looking for the environmental pressures that may have selected for the adaptation, and attempting to discern the likely functions served by the adaptation during the evolution of the adaptation. In the next section, we review briefly the temporal sequence of human evolution, with the purpose of identifying a possible temporal location for the emergence of the symbolic self.

\section{A Brief Review of the Temporal Sequence of Human Evolution}

'Me exact temporal sequence of human evolution is a matter of much debate. We do not intend to convey 
the impression that the time course of human evolution that we use in this article is exactly correct or even, given the existing data, that it is the onlyjustifiable time course. Rather, we attempt to use a time course that is plausible, given existing theory and data.

DNA-RNA hybridization experiments (Sibley \& Ahlquist, 1984) suggest that hominids split from the common ancestor of chimpanzees, bonobos, and humans approximately 6,3 to 7.7 million years ago. The earliest members of the human family are considered to be the australopithecines, who are thought to have appeared about 5.5 million years ago. The oldest known (confirmed) fossils of Australopithecus are approximately 3.8 million years old (for a review of archaeological evidence, see Day, 1986). The Earth was a restless place during these periods, and it is thought that there was a general cooling of the climate from 3 to 2 million years ago. The home of the australopithecines, east and south Africa, was marked by shrinking of the forests and expansion of the savanna grasslands. It is reasonable to speculate that these climatic changes induced the australopithecines to move from forest to savanna.

The date of the exact transition from the australopithecines to early humans is unclear. An early human, Homo habilis, may have coexisted with the australopithecines (Leakey, 1966). Alternatively, early humans may have been direct descendants of the early australopithecines. However, regardless of the exact origin, it is fairly clear that rapid changes in the size and organization of the human brain coincided with the appearance of Homo habilis (Falk, 1987; Holloway, 1975; Tobias, 1971). The data suggest that this trend continued through time, and it is reasonable to speculate that the next human species in the timeline, Homo erectus, had a highly evolved brain (McHenry, 1992).

Homo erectus appeared by at least 1.8 million years ago. These individuals would have been subjected to the continuing selection pressures accompanying the transition from forest to savanna. Homo erectus is thought to have given rise to Homo sapiens, who appeared approximately 300,000 years ago (and maybe as early as 800,000 years ago). Homo sapiens likely spread from Africa and replaced archaic hominids (e.g., Neanderthals) elsewhere-a scenario supported by several sources of evidence (i.e., fossil and archaeological records, data on the genetic associations and diversity of present-day humans; Klein, 1992). Homo sapiens sapiens appeared by at least 100,000 years ago and is the human species found on the Earth today.

Food availability is one of the major selection pressures on a species, and the method of hominid food procurement has undergone change. Tooth wear patterns and other evidence are consistent with the idea that Homo habilis was primarily a scavenger. By comparison, the evidence suggests that Homo erectus was primarily a hunter. One might speculate that the move to the savanna and climatic changes caused early humans to "cast a wider neC (e.g., through hunting) to obtain food. Later in this article, we review the suggestion that this change to hunting, and the consequent cognitive changes, helped to set the stage for the evolution of the symbolic self.

However, these changing food procurement techniques were also a part of an evolving social culture. For example, there is evidence suggesting that Homo erectus lived in stable and interdependent small groups that were parts of larger hunter-gatherer or horticultural societies. Further, hominids used home base areas by the time of late Homo erectus or early Homo sapiens (probably by the Pleistocene epoch-no later than 1.7 million years ago; Isaac, 1978). These lifestyle patterns suggest that extensive social exchange (i.e., cooperation between or among individuals for mutual benefit) was likely a major contributor to survival (Trivers, 1985). Later in this article, we examine the notion that this social lifestyle was a major contributor to the evolution of the symbolic self.

\section{When Was the Symbolic Self Selected? Temporal Origin of the Symbolic Self}

Evolutionary psychologists are concerned with the temporal context of the evolution of a trait. Given the anthropological and biological evidence, the late Pleistocene epoch (inhabited by Homo erectus) is an excellent candidate for the time period in which a symbolic self-one that bears content, structural and functional similarities to the modern symbolic self-emerged.' It is especially relevant that during this time period (a) the brain exhibited substantial increases in capacity and complexity, (b) hunting apparently became an increasingly important method of food procurement, and (c) humans began to exhibit signs of increasing complexity in social organization.

Dating the origination of the symbolic self in the late Pleistocene epoch is a rough and controversial guess. One cannot exclude the possibility that the symbolic self may have appeared earlier, especially given the evidence suggesting that relatively complex social behavior in humans may predate Homo erectus. Indeed, without more details about the aspects of social behavior being focused on, one could view social behavior as an ancestral trait that was in place before the hominid lineage broke off from its evolutionary precursors. Similarly, even if one relates the emergence of the symbolic self to the rapid evolution of the human brain,

${ }^{9}$ Although the two may be linked, there is no necessary relation between the evolution of consciousness and the evolution of the symbolic self Readers should consult Jaynes (1976) for one view of the evolution of Readers should consult Jaynes (1976) for one view of the evolution of
conscious thought and an evolutionary timeline that is somewhat different from our own. 
one cannot exclude the possibility that the pre-Pleistocene human brain had already evolved sufficiently to allow the emergence of the symbolic self.

\section{A Focus on Selection Pressures}

Nonetheless, despite these obvious difficulties, placing the origination of the symbolic self during the late Pleistocene epoch is plausible. We believe that the convergence of these three events (brain expansion, hunting, and social complexity) is particularly crucial. In the following sections, we review two explanations for the emergence of the symbolic self during this time period. The first of these explanations is that the symbolic self is a consequence of the enhanced cognitive capacities that emerged in response to ecological pressures. The second explanation is that the symbolic self is a consequence of the problems associated with the social lifestyle of early humans."'

\section{Ecological Pressures Perspective}

There is certainly reason to link the evolution of sophisticated cognitive capabilities to food acquisition issues. For example, contemporary data suggest that problems in foraging and finding food are associated with increased encephalization. The irregular distribution of food supplies in time or space is associated with larger brain-body ratios among frugivore primates (Milton, 1981, 1988). Furthermore, omnivorous extractive foragers have the largest brain-body ratios among primates (Gibson, 1986; Parker \& Gibson, 1979).

Recall from our timeline that the early humans (i.e., Honto habilis) were likely foragers and scavengers who spent a significant amount of time in the forest. Thus, the basic mental apparatus needed for solving foraging problems in the hominid line likely goes back to as early as 5 million years ago (Trivers, 1985). The early hominid forest dwellers (Homo habilis) were likely equipped with a basic mental apparatus suitable to foraging, as are pongids today. Such skills include recognizing food, searching for food, and handling/processing food. Recognizing food involves being able to construct a taxonomy of food items along the dietary-nondietary dimension (Burton, 1984). That is, these frugivore hominids

${ }^{10}$ George Herbert Mead's concern with placing the emergence of the self, language, and consciousness within an evolutionary framework should be noted. Mead discussed the biological prerequisites of symbolic interaction and emphasized the continuity of human and other animal species (see Baldwin, 1986). Like Mead, we are also concerned with placing the selfconcept in an evolutionary framework. Unlike Mead, we intend to offer concrete theoretical accounts regarding the evolution of the selfconcept. One of these accounts, the social pressures perspective, bears similarities to Mead's thinking. were able to categorize hundreds of food types as poisonous versus nonpoisonous, edible versus nonedible, nutritional versus nonnutritional, and medicinal versus nonmedicinal ( $\mathrm{R}$. Fox, 1980; Galdikas \& Vasey, 1992). Also, recognizing food involves being able to remember each food item for its dietary value. Finding food requires memory for how to get to irregularly distributed food patches, and for the shortest route to food patches. Stated otherwise, finding food requires good spatial memory or cognitive mapping (Menzel, 1978; Wallace, 1989). The purpose of handling/processing food is to render the food edible prior to ingestion. Handling/processing ranges from removing food from a branch to extracting edible but embedded food, often through the use of tools (Gibson, 1986; Parker \& Gibson, 1979). Successful handling/processing requires cognitive representation and anticipation of future events.

It is possible that the evolution from Homo habilis to Honio erectus was partly a consequence of the challenges that the ancestral savanna niche posed to the latter species. For Homo erectus, hunting was an important source of food. Thus, Honto erectus was faced with a task that was quite different from the lifestyle of earlier hominids: the pursuit and killing of living and mobile animals, possibly including big game (i.e., more than $15 \mathrm{~kg}$; Isaac, 1978). This was an extraordinarily difficult task for an animal that was not well equipped for survival and reproduction on the open savanna. That is, given its arboreal background, early Homo erectus was probably a terrible hunter. As R. Fox (1980) put it:

Very little about ... our ... forebears could have inspired confidence ... not the stature, the speed, the strength, the ferocity, or even the mental equipment. And the answer to this ultimate success can only lie in the very helplessness of the original creature. (p. 175)

Homo erectus may have compensated for their bw hunting competence by constructing weapons. Across time, proficiency at weapon use may have contributed to increases in motor dexterity (S. Kaplan \& R. Kaplan, 1978). But even so, these weapons were limited to an effective range of no more than $30 \mathrm{ft}$ (Laughlin, 1966). Thus, it was imperative to approach the target closely and to be skillful in stalking. This necessary skill is reflected in the hunting description of Laughlin (1966):

The hunter is concerned with the freshness of the track and the direction in which he is moving. He wants all possible information on the quarry's condition: its age, sex, size, rate of travel, and a working estimate of the distance by which the animal leads him. In the final stages, when he is closing with the animal, the hunter employs his knowledge of animal behaviour and situational factors relevant to that behaviour in crucial fashion. For all birds, animals and fish the hunter must estimate flight distance, the point at which they will 
take flight or run away. Conversely, with animals that are aggressive, he needs to interpret any signs, raising or lowering of tail, flexing of muscles, blowing, or salivation, etc., that indicate an attack rather than a flight. (pp. 308-309)

These hunting skills relied, no doubt, on the already evolved capacities of recognizing food, finding food, and handling/processing food-evolution often uses old traits when building new ones. However, the demands of hunting required these capacities to evolve by several orders of magnitude.

First, for the organism to cope with disparate and fast-changing pieces of information, perceptual capabilities had to improve. The organism had to register mentally an accurate image of a moving target (S. Kaplan \& R. Kaplan, 1978). Hence, the capacity to mentally orient objects in space rapidly and accurately became critical: Mental orientation and mental rotation aided prediction of the prey's actions.

Along with the demands on the perceptual system came additional demands on the memory system. Prey recognition had to occur in matter of seconds, or even milliseconds. To accomplish this, several memory capabilities had to improve. First, memory capacity had to expand because of the need to store information about a large number of possible food sources. Memory organization also had to improve, because an efficient cognitive taxonomy of prey facilitates recognition. In addition, early humans needed to have the ability to form abstract categories (i.e., categories "remote in time and space from the immediate flux of sensations",. Griffin, 1976, p. 5) and to place objects into those categories speedily. Furthermore, cognitive mapping capabilities had to improve. Early hominids covered a territory of 100 square miles or more (S. Kaplan, 1992) from a home base. They acquired a vast repertoire of environmental knowledge regarding distribution of prey, patterns of prey movement, and shortcuts that could benefit stalking. This information had to be stored and catalogued efficiently. Highly refined cognitive maps would save on energy and time when trapping and hunting (Peters \& Mech, 1975). Also, cognitive maps would ensure adroit and safe escape upon appearance of predators (S. Kaplan, 1976).

The demands of the environment may have also contributed to the evolution of both automatic and controlled processing capabilities. In an environment rewarding speed, fast-acting (and usually accurate) decision rules enhance adaptive fitness (R. Fox, 1992). From cognitive perspective, speed is best guaranteed by the operation of automatic processes. Thus, those elements of existence that required speed (e.g., prey and predator perception, recognition, and evaluation) likely were subject to automatic control "very much like the control of the breathing process" (S. Kaplan, 1992, p. 585). This capability may be retained in the form of gut feelings"
(Darnasio, 1994), rapid heuristic use or category-based judgments (Brewer, 1988; Fiske \& Netiberg, 1990), or preference development without extensive thought (Schmidt-Atzert, 1988; Zajonc, 1980).

However, quick responding does not always enhance adaptive fitness. The keystone of evolution is that it is guided by the environment, and quick responding is likely to be adaptive only when the organism has to act under time constraints. In fact, there are circumstances in which quick responding may lead to a reduction in adaptive fitness. These circumstances were especially applicable to early humans.

One of these circumstances is when a stimulus is novel, or when circumstances are new. Examples of new stimuli are unfamiliar prey, prey protected unusually well by conspecifics, or new landscape challenges. In such instances, the stimulus is not a good fit to a preexisting conceptual category, so no effective rapid response can be made. The move of humans from an old environment (forest) to a new environment (savanna) and a new lifestyle (hunting) involved many novel stimuli, and the capacity to engage in thoughtful analyses in those situations was very important. Because of their wide range of movement and social habits, early humans were also often in the midst of new situations involving, in part, social dilemmas. Examples might be trying to figure out how to carry large prey to the home base, whether consumption of prey could be postponed until arrival at the home base (e.g., depending on distance from the home base and the condition of the prey), and optimal methods of food preparation."

Unfamiliar situations of high personal relevance call for careful attention to the specific features of the stimulus, deliberate and time-consuming analyses of the situation, effortful attempts to match a stimulus with preexisting categories, and, perhaps, the creation of new categories to accommodate the stimulus. In such circumstances, the organism is often obligated to plan strategically and make predictions. That is, the organism needs to account systematically for a large number of variables, evaluate possible and desirable outcomes, and engage in hypothetical reasoning in which the fit of various behavioral responses to environmental demands is estimated.

${ }_{11}$ Hunting typically requires (a) carrying the game to the home base (a trip facilitated by the evolution of bipedality), (b) postponing the consumption of food (given that food has to be carried to the home base first), (c) preparing food for consumption (which requires the fabrication of new tools), and (d) food sharing (through language; Isaac, 1978; MeGrew \& Feistner, 1992). Some of these behavion difference between hommids and pongids. For other behaviors (i.e., preparing food for consumption, food sharing), the difference is quantitative. The latter class of behaviors may he the product of indirect rather than direct selection; that is, such behaviors may have evolved as a by-product of domain-general cognitive abilities due to increased encephalization (Galdikas \& Vasey, 1992). 


\section{THE SYMBOLIC SELF'}

In short, these circumstances call for controlled processing. This style of processing can override or bypass automatic processing (Mandler, 1975). Controlled thinking allows the organism to move beyond the simple consideration of alternatives stored in memory to the generation, internal consideration, and selection of entirely new alternatives. In addition, controlled thinking allows the flexible and online revision of plans based on additional information that is retrieved from long-term memory, from the environment, or even from the imagination. In novel circumstances, the use of controlled processing (conscious thinking) is a useful survival strategy."

Implications for the evolution of the symbolic self. The ecological pressures perspective offers the possibility that human cognitive capabilities critical for the symbolic self evolved as a consequence of the multiple environmental challenges-especially in the domain of food acquisition-that confronted early humans repeatedly. These capabilities evolved independently of social pressures. One reasonable issue that might arise from our prior discussion of this perspective (and that arises later in our discussion of social factors contributing to the evolution of the social self) is why these arguments do not apply to other organisms. That is, some might claim that other organisms surely have undergone similar lifestyle changes during the course of evolution, and one might expect those organisms to exhibit the same kinds of cognitive abilities that evolved in humans.

One appropriate response to this issue is that evolution does not create traits magically. Instead, evolution works by modifying existing capabilities. Thus, one might speculate that other organisms who have been exposed to similar selection pressures did not develop similar cognitive capabilities because the precursors of those capabilities were not in place. In this regard, it is useful to recall that we have already noted that the early hominid forest dwellers (Homo habilis) were equipped with a mental apparatus suitable to foraging. This mental apparatus likely included a good memory for various edible food sources, cognitive maps to direct travel between those sources, memory for when those sources were and were not available, and even the capability for primitive tool use. In short, the adaptations of humans to the selection pressures imposed by climatic and lifestyle changes reflected the unique biologically determined capabilities and characteristics of their ancestors.

But how does this increase in cognitive capacity relate to the symbolic self9 First, the capacity to use abstract symbolic

${ }_{12}$ Of course, controlled thinking standards evoked by experts) is not guaranteed to reach errorfree decisions and choices (T. D. decisions. In fact, deliberate, Wilson, Dunn, Kraft, \& Lisle, effortful, and analytic thinking can 1989).

lead to poor (as judged by reasoning is critical to the evolution of a symbolic self: Without this capacity, no symbolic self could emerge. However, in our view, the emergence of such cognitive capabilities was a necessary, but not a sufficient, contributor to the emergence of a symbolic self. That is, the evolution of these cognitive capabilities merely set the stage for the symbolic self.

The emergence of the symbolic self likely was a further step in enhancing the adaptive fitness of the organism. That is, the adaptive utility of enhanced cognitive capacities may become even greater when guided by a symbolic self. Let us elaborate on this point. The content of the symbolic self is characterized by memory of past achievements and by achievements planned for the future. Such a self-system can be adaptive to the extent that it can serve as a useful guide to increasing the effectiveness of behavior. This can happen in several ways. For example, the use of the symbolic self can serve directly as an aid to decision making: Awareness of the content of the symbolic self can aid in the decision to join maximal resource utility bands, or bands that match one's personal goals."

Furthermore, one of the consequences of having a symbolic self is that one can reflect on it and consider oneself in alternative times and circumstances (Markus \& Nurius, 1986). This is not simply idle thought. As our research review indicates, reflecting on the symbolic self facilitates both short-term and long-term goal setting (Rosenberg, 1988) and motivation to pursue various life tasks (Cantor et al., 1986). Therefore, such future-oriented thought is likely to be adaptive. That is, if the consideration of the symbolic self in a future context produces motivations and behaviors consistent with that thought, and if such future-oriented thought is associated predominantly with positive emotions (Staats \& Skowronski, 1992), then the motivational and behavioral impetus of the behavior engendered by such future-oriented thought will work toward achievement of those positive emotions. In short, thinking about oneself in a variety of future contexts and situations will lead to behaviors that are adaptive in those contexts and situations.

This view of the nature and origin of the self has implications for several issues. For example, one important implication pertains to the relation between the private self and the public self. The ecological problems approach to the symbolic self implies that the construction of the symbolic self need not be influenced (at least initially) by social factors; instead, it can be constructed privately by the individual. Once constructed, the indi-

${ }_{13} A$ bandis defined as "a numberof animals whichremain together in or separate from a larger unit and mostly interact with each other" (Kuminer, 197 1, p. 40). 
vidual can convey this private self to others, a process we term projected appraisal. Hence, in this view, the individual determines others' perceptions of him or her so that these perceptions are in accordance with selfperceptions (Kenny \& DePaulo, 1993). Social feedback plays a secondary role, perhaps serving to verify the validity of the projected self (Sedikides \& Skowronski, 1995).

This approach also has implications for self-esteem and emotion. Generally speaking, one way to engage in self-evaluation is to match self-ideals or plans against the outcomes obtained. If such an evaluation indicates a reasonable match, then positive self-evaluation (or self-esteem) and pride will result. On the other hand, if the match indicates that behavior was unsuccessful, it will result in negative self-esteem and shame.

These emotional responses probably served to enhance the adaptiveness of the symbolic self. First, they could have provided immediate feedback with regard to the current state of goal achievement and, thus, helped to redirect action accordingly (i.e., persist along the same lines or take corrective action). Second, the emotional responses may have provided crucial feedback regarding the efficiency of effort allocation. Experiencing positive self-esteem in the face of challenge is informative with respect to the appropriateness of an approach response. Exp eriencing negative self-esteem in the face of challenge is informative with respect to the appropriateness of an avoidance response. In short, self-esteem could have served as a gauge for goal attainment.

Another function that self-esteem and self-conscious emotions likely served was to act as a protective buffer for the symbolic self (Solomon, Greenberg, \& Pyszczyriski, 1991). Low self-esteem is an uncomfortable state. In order to avoid this state, appropriate perceptual and cognitive defense mechanisms may develop. Thus, because the symbolic self is generally positive (Brown, 1993), an individual may be particularly attentive to positive feedback and may ignore threatening feedback. Further, high self-esteem can be maintained by evaluating the symbolic self in an idiosyncratic manner-that is, by using criteria on which the symbolic self showed respectable performance (Dunning, 1993).

\section{Social Pressures Perspective}

The rise of stable social groups is a second explanation for the evolution of a symbolic self. This perspective suggests that the symbolic self is formed, in large part, by internalizing the way members of a social group perceive and evaluate an individual-a process termed reflected appraisal by symbolic interactionists. This type of thinking about the self is only possible in the context of sophisticated cognitive abilities. Once those abilities have been achieved, social interaction allows the construction of a symbolic self.
The social pressures perspective is based on the assumption that social problems posed the most powerful selection pressures for Honto erectus, and the symbolic self was an evolutionary response to social problems. More specifically, this perspective embodies two assumptions. First, ecological factors (i.e., predation and predator pressures) played a deterministic role in shaping social systems, which in turn ultimately led to the evolution of the symbolic self. Second, and most important, it was social pressures deriving from the group lifestyle that led directly to the evolution of the symbolic self (Brewer \& Caporael, 1990; Caporael \& Brewer, 199 1; Maryanski \& Turner, 1992; D. S. Wilson \& Sober, 1994).

As noted, there is evidence that early Homo erectus lived in social groups in which hunting parties ranged from stable home bases. From an evolutionary perspective, group living is associated with several benefits.

First, group living is highly advantageous when it comes to predation. Group living improves hunting efficiency: Individual group members can pool and coordinate their resources for increased hunting success. Also, group living elevates the chances for survival and reproductive success of the individual group members through food sharing; for example, successful hunting of big game creates surplus meat, which can be shared among group members (McGrew \& Feistner, 1992).

A second general advantage of group living is that it reduces predator pressures (Alexander, 1974). Group living (a) increases overall environmental vigilance and thus provides earlier detection of, and warnings about, predators (Crook \& Gartlan, 1966, Eisenberg, Muchenhirn, \& Rudran, 1972; Van Schailc, 1983); (b) reduces the risk of any given group member's being preyed upon by predators (Clutton-Brock \& Harvey, 1977; Crook, Ellis, \& Goss-Custard, 1976), and (c) improves defense against predators through various forms of predator mobbing (Chan, 1992).

A third advantage of group living is that it affords cooperative defense of key resources, such as food sources and mates, against rival groups of conspecifics (Alexander, 1974; Wrangham, 1979). 14

The advantages of group living have several implications for early humans. One implication is that Homo erectus probably lived in relatively large groups. The reasoning behind this conclusion is as follows. Group size is likely to be larger the higher the predation risk. Terrestrial species living in an open-country savanna environment, such as Homo erectus, were at high pre-

14 Group living is also associated with several costs, such as (a) intragroup competition for limited resources (e.g., food, mates, shelter), (b) increased conspicuousness to predators, and (c) increased risk of infection by parasites or contagious diseases (Alexander, 1974). 
dation risk (Alexander, 1974; Crook \& Gartlan, 1966; Eisenberg et al., 1972; Kummer, 1971). A second implication is that sexual dimorphism should be exhibited. Males should be larger and have greater fighting ability than females (Clutton-Brock \& Harvey, 1977; Crook \& Gartlan, 1966; Eisenberg et al., 1972). The relatively larger size of males likely caused the males to conduct most of the hunting, particularly for large game. Although they probably did not often hunt, females likely performed several tasks equally important to group survival-such as food gathering, food preparation, child care, and child protection. In fact, our assumption is that all of these tasks required the fostering of interdependent personal and social relationships, a process that contributed to the evolution of cognitive capacities and the symbolic self. Finally, a third implication is that the group ought to have some form of organization (Eisenberg et al., 1972). Such organization is typically exemplified by status differentiation. Given the male's advantage in weight and strength, it is assumed that males would have tended to be of higher status in group governance. In any case, the point is that the group was differentiated by status.

It is important to note that we argue that status differentiation did not take the form of a strict and simple dominance hierarchy of the type observed in many animal species. In many ways, such strict group structures simplify social relationships-one responds to others based on their fixed social rank. These strict group structures may not create the social pressures and, consequently, may not select the cognitive capacities that can lead to the evolution of a symbolic self.

Instead, we argue that humans maintained a relatively loose and flexible social structure, one in which status was often quite changeable from moment to moment and from situation to situation. In such structures, one does not automatically know where one stands in the group. Instead, one's position or status changes with changing circumstances and changing alliances. Such a flexible structure places heavy cognitive demands on the individual: To be successful, the individual must monitor constantly other group members and the current situation. In addition, foresight and planning also become useful atributes, especially if one attempts to move to a position of power or to solidify a position of power in the social hierarchy. Thus, in our view, it is the relatively loose and flexible group structure of humans that is crucial to the evolution of a symbolic self. Such a structure made social organization and coordination a complex affair, producing the selection pressures that helped to lead to the evolution of the capacity for a symbolic self.

Let us examine these social pressures more closely. A high level of social complexity brings the opportunity for several types of interactions (Galdikas \& Vasey, 1992; Hinde \& Stevensen-Hinde, 1976). First, one might expect interactions among individuals. Examples of such interactions are feeding, grooming, playing, traveling, mating, and fighting. Second, one might expect relationships among individuals. Relationships, which are long-term and transcend generations, determine the nature of interactions (i.e., who does what to whom, how often, and under what conditions) and can be based on several factors, including kinship, sex, age, and individual history. Third, one might expect to encounter social structures characterized by generally endorsed rules. These rules may specify the various types of status differentiation and alliance systems. Given that Homo erectus used stable home bases-a qualitatively unique attribute of hominids-one might expect these rules to also be relatively stable.

One such social rule is that of cooperation (Guisinger \& Blatt, 1994; Simon, 1990). Cooperation is beneficial to both the giver and the recipient. The giver may incur short-run costs, but, because the recipient often reciprocates, in the long run the benefits outweigh the costs. Cooperative behavior can lead to the formation of reciprocal dyadic alliances or friendships (Trivers, 197 1). " Triadic relationships were also possible. These relationships can lead to new complexities, such as coalition building and maintenance.

Often, individuals are induced to enter cooperative alliances because of external threat from others. In entering dyadic or (especially) triadic alliances to counter such threats, the organism must assess (a) the type of the relationship between the potential allies and opponents, (b) the competitive ability of the opponent and the opponent's allies, (c) kin relationship to the opponent, (d) risk of injury to self or to the solicited party from opponents if support is denied, and (e) whether joining the alliance is overall more beneficial that abandoning it (Harcourt, 1988).

Within-group cooperation produces new challenges. A group needs to fulfill several functions well in order to exist; such functions include role differentiation (roles are defined in terms of social conduct according to reciprocal expectations; Benedict, 1969), coordination of individual effort, conformity with rules, group loyalty, and fear of social exclusion.

All of the aforementioned social factors suggest that groups can become complicated. Thus, one might speculate that, in Homo erectus, individuals who had cognitive and dispositional traits that caused them to excel at these group functions had a reproductive advantage by gaining access to food, mates, and protection from predators. In this manner, identification with the group and playing by the group rules served the interest not only of the group but also of the individual (Alexander, 1987; Brewer \& Caporael, 1990; Caporael \& Brewer, 1991; D. S. Wilson \& Sober, 1994). By corn-

15 special form of cooperation that we do not consider in this

article is kin selection, that is, altruistic behavior toward kin that resulted in their selective advantage (Hamilton, 1964). 
parison, individuals who were not good at group functions (i.e., individuals whose ativities were disruptive to group functioning) were at a competitive disadvantage: They were likely to be ostracized and put on the fringes of the group and therefore were more vulnerable to predators or the consequences of low resource allocation (Baumeister \& Leary, 1995; Baumeister \& Tice, 1990; Buss, 1990ab).

Certainly, not every group member cooperates at either the dyadic or the group level. Placing immediate personal benefit over long-term group benefit through nonreciprocity or cheating can be lucrative if the members of the group continue to respond cooperatively toward the cheater. This allows the cheater to maintain a consistent advantage. Of course, obvious deviance from reciprocity is not well tolerated, so that a successful deviant or cheater is one who needs Machiavellian intelligence (Byrne \& Whiten, 1988). To be successful at cheating, individuals with this trait need to possess a relatively high level of social intelligence. That is, they need to be capable of monitoring the behavior of samegroup conspecifics, changing their own behavior as a function of the social situation and engaging in such behavior in a nonobvious fashion.

From the group's perspective, it is advantageous for rule-abiding group members to be able to prevent deviance or detect cheating. In fact, humans may have a specialized "detection of cheaters" cognitive algorithm that affects the way in which they approach social exchange situations (Cosmides, 1989; Cosmides \& Tooby, 1989). Such detection would presumably ensure that an individual's noncooperative behavior was not detrimental to the success of a group.

Nonetheless, there are circumstances in which noncooperative interaction strategies (e.g., individualism or competition) can be advantageous. Obviously, if one can overwhelm others and garner resources for oneself at relatively low cost, competition can be effective in resource acquisition. This competition can take two major forms. The first form is intergroup competition, that is, competition against other groups of conspecifics. Given the sexual dimorphism in humans, it seems reasonable that intergroup competition was carried out by the males of each group, in an attempt to defend females, offspring, and territory.

Note that there is a paradox in this competitive strategy: Successful intergroup competition is often made possible through intragroup cooperation. That is, this intergroup competition strategy has the best chance of being successful if the group members cooperate in (a) attracting and recruiting multiple females to the group, (b) inducing the males to breed with the females, (c) making sure that the territorial resources enhance the chances that the offspring reach reproductive maturity, (d) maintaining ingroup solidarity and mutual support, (e) defending the territory against adversaries, and (f) retaining the male offspring in the natal group (Ghiglieri, 1989).
The second form of competition is intragroup competition (Axelrod, 1984). This intragroup competition can take several forms. A very important form is intrasexual competition for suitable mates and its natural accompaniment, epigamic selection (i.e., interactions between the sexes, such as mate attraction, mate selection, and mate retention; Huxley, 1938). Intrasexual competition places several cognitive demands on the individual (Galdikas \& Vasey, 1992; Parker, 1987). Sexually reproductive adults in a group must (a) remember and readily recognize their relationships with other adults in the group (e.g., rank, kinship), (b) monitor the rank and physical condition of potential competitors (e.g., to stay away from conflict with higher ranked group members and to try to control the access of others to potential mates), (c) be capable of deceiving higher ranked competitors, (d) monitor the spatial distribution, sexual receptivity, and fitness of potential mates, and (e) exhibit their physical and social prowess in order to attract potential mates. In addition to performing these tasks, adult females must also safeguard against forced-copulation attempts on the part of males.

The upshot of this discussion is that Homo erectus was likely confronted with numerous complex social problems: dyadic, triadic, or group-level cooperation; smooth group functioning; cheating; detection of cheaters; intragroup (and, particularly, intrasexual) competition; and intergroup competition. Given that Homo erectus lived in large, flexibly structured social groups, these social problems were probably much more substantial than the problems that are faced by species with more rigid social structures. The social pressures view suggests that it was these pressures that contributed to the expansion of cognitive abilities in early humans and, later, to the evolution of the symbolic self.

Implications for the evolution of cognitive capacities and for the evolution of the symbolic self. At least two lines of evidence suggest the validity of this position. First, social complexity is correlated with brain-body ratio among primates (controlling for diet). That is, the relative brain sizes of polygamous multimale-multifernale primate species are larger compared to the brain sizes of monogamous species (Sawaguchi, 1990).

The second line of evidence comes from physical anthropology and indicates that the expanded and lowered pharynx (which is a physiological necessity for articulate speech) evolved in late Homo erectus or early Homo sapiens. The Australopithecines had the high larynx typical of monkeys, and the position of the larynx in early Homo members was apparently intermediate. This physiological shift (as well as corresponding brain changes; McHenry, 1992) suggests that evolution favored those with verbal communication skills. In the context of an increasingly complex social life, the emer- 
gence of communication skills makes sense. Communication skills allow establishment of sophisticated plans for social action (e.g., group-wide functions, intergroup competitive encounters), help to create and maintain long-term relationships, and aid in the socialization of offspring (Zeller, 1992).

The downward movement of the pharynx and increasing brain differentiation also suggest increasing cognitive capabilities, particularly the evolution of language, and the symbolic capabilities that go along with linguistic abilities. Cognitive and linguistic ability in the context of a complex social structure are consistent with the emergence of the symbolic self. For example, in verbal and nonverbal exchanges among group members, the symbolic self would become a communication referent (Chomsky, 1972; Fodor, Bever \& Garrett, 1974; Hattiangadi, 1973) as when duty assignment during hunting expeditions was taking place or when prey was split among band members (e.g., one for you and two for me). When used in such a way, the self acquires a linguistic referent and categorical substance, and does so for both the self and for the others in the interaction.

Further advantage can be gained from the evolution of skills that are necessary for social coping, such as an advanced capacity for perspective taking or role taking. Such capabilities would allow the individual to better anticipate and affect others' behavior. One immediate consequence of this perspective taking is the acquisition of the ability to think of oneself as others do in concrete linguistic terms. Given (among primates) the uniquely complex early human social organization, this ability to think of oneself and cognitively represent oneself as multiple others would represent oneself likely evolved quickly, efficiently, and to a greater degree in those with symbolic reasoning capabilities.

Furthermore, this perspective-taking capability would exert subsequent pressure for further increasing cognitive capacities. After all, these early humans interacted with a variety of other conspecifics on a daily basis. To adopt the perspective of each of these others, an individual would need to keep track of the way each fellow group member evaluated him or her. Thus, the individual would need internal representations of multiple others' opinions. It is easy to see how this process, by itself, could lead to the evolution of a malleable symbolic self, one that would take on many different contents and structures.

There is still more complexity to be had. Individuals sometimes engage in sophisticated deception. To deceive, the organism must (a) remember how the other group member(s) thought of her or him and (b) improvise a different persona to present to the fellow conspecific. To improvise a different persona, the organism must rely on the symbolic self; that is, the organism must magnify an aspect of the symbolic self and present it to others. This process may even involve self-decep- tion (Gur \& Sackheim, 1979; Sackeim, 1983), which may be facilitated through denial and repression (Nesse \& Lloyd, 1992). Self-deception is adaptive because it conceals the truth (or ulterior motives) to the deceiver; consequently the deceiver is better equipped to lie without detection (i.e., leakage from nonverbal cues may no longer occur).

Collectively, these social processes suggest a means for the evolution of several of the typical facets of self-knowledge. In particular, these social processes lead directly to the emergence of the public self, which refers to the self as presented to an external audience. For example, the public self may involve one's behaviors, clothing, or facial expressions (Baumeister, 1982; Leary, 1995; Schlenker, 1980). The rationale for the evolution of this type of self-knowledge is straightforward: In order to communicate with others in a complex social environment, to enact the necessary social roles, and to influence effectively others when necessary, one has to develop a knowledge of how to manipulate the presentation of self to others.

Processes as sociated with the evolution of the public self can also contribute to the evolution of private self-knowledge. First, the public self can lead directly to the formation of the private self through the process of biased scanning (Tice, 1992). That is, aspects of the public self (i.e., aspects on which an audience focuses) are likely to receive attention and thought. This will result in these aspects of the public self becoming highly accessible in memory, which in turn could lead to internalization. If this occurred, then these aspects of the public self would obviously become aspects of the private self. Second, social interaction leads to the development of expectations. To coordinate with others, an individual must develop ideas of what to expect from others-and of what others expect from the individual. To anticipate how others will respond, one needs to know the social roles and the functions that they fulfill (Rosenberg, 1988). With the evolution of the ability for abstract thinking, individuals' perceptions of their own general roles and skills could have been subsumed under a person category (Ostrom, Pryor, \& Simpson, 1981) that represents the various aspects of interactions with others and the circumstances of those interactions. Hence, social interaction with others could lead directly to the evolution of the self as an object of knowledge-seeing yourself as others see you-and this capability could have evolved as a result of selection pressures favoring those with high ability to coordinate actions with others.

To summarize, the social pressures position argues that the symbolic self (a) arose out of complex social interaction processes, especially the need for perspective taking (Rosenberg, 1988), (b) was facilitated by the emergence of linguistic capabilities, (c) was shaped by the way other conspecifics perceived the organism-that is, the private self was shaped by the public 
self through the process of reflected appraisal (Stryker \& Statham, 1985), and (d) was in the service of impression management (Barkow, 1989; Vine, 1987).

The social evolution of the symbolic self has several implications for other issues in the self literature. The first of these concerns the possible functions of self-esteem. Self-esteem may act as a sociometer (Leary, Tambor, Terdal, \& Downs, 1995). That is, self-esteem can aid in monitoring the evaluations of other conspecifics, informing the organism of the impending danger of rejection or social ostracism. Such danger would accompany the individual's failure to carry out groupwide important goals, or to abide by the group rules. In a similar vein, self-esteem may serve as a sociometer not only for the individual as a unique entity, but also for the individual as a group member. Group self-esteem may gauge how well a given band performs compared to competitive bands of conspecifics (Barkow, 1989).

Furthermore, self-esteem can serve as a cue regarding the relationship of the organism to the other conspecifics. Ibis would likely lead to the avoidance of competitive encounters for limited resources (Barkow, 1989). For example, being ranked highly in the dominance hierarchy leads to a symbolic self representation that is homologous (i.e., has the same evolutionary root) with high self-esteem (Barkow, 1989). This is illustrated by the way in which individuals high in a dominance hierarchy (i.e., individuals with high self-esteem on the dimension of physical prowess) indicate their self-esteem on that dimension through posturing or threats. This displaces lower ranked (i.e., low-self-esteem) individuals. For similar reasons, self-esteem may serve useful functions for individuals occupying low positions in the hierarchy, because it also helps deter competitive encounters; that is, these individuals defer to other high-self-esteem group members.

Undoubtedly, individuals occasionally receive negative feedback from other group members. Several mechanisms could have evolved to allow individuals to minimize the impact of negative social feedback. Examples include ignoring, denying, or repressing the feedback through (a) self-deception, (b) derogating the feedback or the evaluator, (c) countering the feedback with aspects of the symbolic self that were positive and feedback-irrelevant, and (d) using idiosyncratic criteria to arrive at different evaluations of the symbolic self than those produced by the source(s) of the feedback (Brown \& Dutton, 1995; Taylor \& Brown, 1988). As indicated in our literature review, all of these mechanisms are currently documented by research into the self.

\section{On the Relation Between the Ecological Pressures and Social Pressures Perspectives}

In principle, the two perspectives on the evolution of the symbolic self that we discuss are independent of each other. That is, each perspective emphasizes different selection pressures and, consequently, offers a unique linear account of the evolution of the symbolic self. The ecological pressures perspective focuses on selection pressures related to the individual. This perspective highlights (a) the evolution of the cognitive abilities in response to ecological demands, (b) the consequent emergence of the private self, which later became communicated to others through the mechanism of projected appraisal, and (c) achievement-based self-esteem (i.e., self-feelings depend on efficacy). In contrast, the social pressures perspective stresses (a) the formation of social groups in response to selection pressures, (b) the socially driven evolution of cognitive capacities (including language) that led to the emergence of the public self, which is then integrated into the private self by means of reflected appraisal, and (c) affiliation-based self-esteem (i.e., self-feelings depend on the evaluations of others).

Despite having presented them as independent explanations, these perspectives need not be mutually exclusive. Although conceptually distinct, it is plausible that both cognitive capabilities and the self-facets that accrued (i.e., private self, public self, and self-esteem) evolved simultaneously and in the same temporal period.

As noted, it is possible that one of these processes drove the self-system initially with the other process serving to complete the symbolic self. For example, one possibility is that the private elf was formed first but was later shared socially as a part of human interaction and cooperation, leading to the emergence of the public self. The public self would be open to criticism or praise, and such feedback could have been integrated into the private self, causing self-esteem to be affected by social feedback. Alternatively, consider the possibility that the public self was primary and led to the emergence of the private self and of efficacy-based self-esteem through later reflection and internalization.

We think that, to account for the breadth of the symbolic self, both of the processes that we consider were operating. However, it is unclear to us whether one of these processes was primary and, if so, which one it was. That is, it is unclear which of the processes was essential to the evolution of the symbolic self, and which of the processes merely served to complete the aspects of the symbolic self that we observe today.

\section{The Symbolic Self in a Comparative Context}

In our argument that the symbolic self evolved in response to selection pressures, we have focused on the current functional attributes of the symbolic self and on the selection pressures that potentially contributed to the emergence of the symbolic self. There is, however, one additional source of information available: 
cross-species comparisons. As noted earlier in this article, there is evidence that some higher order primates (i.e., chimpanzees and orangutans) possess an objectifled self. In fact, the recognition that a small number of higher order primate species possess an objectified self is crucial to any argument in which biology plays a role in the symbolic self $s$ evolution. Because of nature's apparent tendency to reuse solutions that work (i.e., see evolutionary biologists' concept of convergence; Elias \& Bortner, 1957), and because other species should be subject to selection pressures similar to those experienced by humans, research indicating that only humans possessed any form of a self would actually be rather damaging to an evolutionary argument. That other nonhuman species possess roughly similar capabilities suggests that an evolutionary origin of these capabilities is a reasonable possibility. Furthermore, that these capabilities are found in animals relatively close to humans on the evolutionary tree suggests that there is a common evolutionary origin for this ability and that in humans the recent selection pressures have pushed this ability far beyond that observed in related primate species.

More specifically, although the existing evidence argues persuasively that some higher order primate species (i.e., chimpanzees and orangutans) have an objectified self, this objectified self seems to be qualitatively different from the human symbolic self. There is reason to believe that the following human capacities are unprecedented in nonhuman animal life:

1. Introspection and self-reflective action.

2. Counterfactual thinking and self-deception.

3. Imagined audiences and invented personae.

4. Humor.

5. Sexual fantasy.

6. Versatile adjustment of the symbolic self (i.e., acquisition of new symbolic selves as a function of sudden appearances of new environmental stressors such as changes in occupational opportunities or onset of either negative or positive life events).

7. Detailed verbal expression of cognitive, affective, and motivational states.

8. Long-term forward planning and long-term self-evaluation (i.e., through autobiography).

9. Knowledge of own mortality and fear of death.

10. Moral argumentation.

11. The formation of conflict resolution institutions that exceed the boundaries of the ingroup (e.g., the United Nations).

Further, given the generally high environmental diversity of human social and nonsocial life, and accepting the notion of the heightened sophistication of the human cognitive system, it follows that the human memorial representation of the self (i.e., the symbolic self) is likely to be richer in content and more flexibly structured than the nonhuman (i.e., the objectified) self.

If one assumes that the symbolic self is a trait that can be selected by environmental pressures, then an analysis of environmental and behavioral differences between humans and their closely related nonhuman primates may lead to insights concerning the evolutionary pressures that served to select for the evolution of the self. One obvious difference is that early humans developed a lifestyle that involved hunting, whereas chimpanzees and orangutans are primarily (although not exclusively) food gatherers. The crucial role of hunting is further implicated by the observation that some of these nonhuman primates exhibit complex social relationships, which leads to the possibility that social pressures are not sufficient for the evolution of the symbolic self.

However, we also believe that the hunting lifestyle is not, by itself, a sufficient explanation for the evolution of a symbolic self. Instead, we believe that the social elements of the early human lifestyle were crucial to the symbolic self $\mathrm{s}$ evolution. Two sources of data are suggestive with respect to this thesis. The first source of data compares the typical patterns of relationships that exist among humans with the patterns that exist among members of other primate species. Observation of human relationship patterns (Rodseth, Wrangham, Harrigan, \& Smuts, 1991, p. 241) suggests that humans usually maintain relationships with dispersing offspring, so that both sexes are embedded in networks of consanguineous kin during their entire lives. This allows the formation of intergroup alliances, especially through the systematic exchange of mates. Also, conjugal families are typically united by male kinship within atomistic communities. Finally, all of these patterns are facilitated by a unique ability to maintain relationships in the absence of spatial proximity.

Perhaps this description of human relationship patterns is not surprising. What is surprising, however, is that these joint characteristics are apparently unique among primates and may be unique in the animal kingdom (Rodseth et al., 1991). Thus, because of their propensity to maintain close ties among family members-even when separated by distance-humans may have more opportunity (and, thus, more selection pressure) to develop a symbolic self, As we have argued, the possession of such a self is adaptive in that it can clearly help an individual chart the complexities that such relationship patterns can present.

A second source that is suggestive with respect to the emergence of a symbolic self is the anthropological data indicating that the transition from Homo habilis to Homo erectus was also accompanied by an increased potential for communication. As Hodos (1986) noted:

To the extent that an animal can use language or other forms of communication to enhance its survival, it has 


\section{SEDIKIDES \& SKOWRONSK}

an enormous advantage over other creatures, and humans are vastly superior to all other organisms in their use of linguistic and symbolic communication. Language plays such a vital role in human intellectual activities of all sorts that any attempt to compare human intelligence to animal intelligence may be largely meaningless. (pp. 85-86)

Empirically, the acquisition of a hunting lifestyle, heightened social complexity, and increased communicative capabilities (e.g., the drop in position of the larynx) were accompanied by enhanced brain development (the evolution of language areas in the brain, as well as the evolution of the frontal lobes of the cortex). As Gould (1985, p. 37) noted, shifts in behavior might be one precipitating cause of evolutionary changes. The possible co-occurrence in humans of these four changes (hunting, social complexity, language, and thinking) gives even more credence to the possibility that the evolution of self might have been driven by a lifestyle shift. Such a shift would have been facilitated by a species whose individual members are able to think about themselves in relation to a group and by communication with other group members. In our view, then, the differences between humans and nonhuman primates-as well as the human historical record-suggest that both the move to hunting and high social complexity were jointly and interactively responsible for the evolution of the symbolic self in humans.

\section{Concluding Remarks}

Evolutionary accounts posit that, to perpetuate the ability for reproductive survival, many human traits evolved in response to environmental pressures. We include the symbolic self among those traits. We are certainly not the first to hold such an opinion. Over 30 years ago, the geneticist Theodosius Dobzhansky (1964) remarked that the self is the chief evolutionary novelty possessed by humans.

We have attempted in this article to produce a coherent case for this position. The symbolic self is a trait that (a) is widely shared among humans (b) serves adaptive functions (c) could have reasonably evolved in response to a number of different environmental pressures, and (d) has appeared elsewhere in the animal kingdom. Although not definitive proof of the evolutionary origins of the symbolic self, these observations are consistent with such a proposal.

Nevertheless, it is certainly the case that much empirical work is needed in order to demonstrate convincingly that the capacity for having a symbolic self has evolved as an evolutionary adaptation. Rigorous tests of particular adaptationist hypotheses should specify:

1. The workings of the symbolic self (e.g., what circumstances should trigger the activation of the sym- bolic self, what information the symbolic self was designed to assimilate, by what decision rules the symbolic self operates).

2. The specific adaptive problems that the symbolic self evolved to solve.

3. The design features of the symbolic self that are uniquely tailored to solving the designated adaptive problems instead of some other adaptive problems.

4. Falsifiable predictions (i.e., predictions that outline the observations to be recorded under the hypotheses and the alternatives)

However, even if the hypothesis that the capacity for symbolic self is an evolutionary trait proves to be valid, this idea does not inform us about the exact content of the symbolic self. Nonetheless, one can speculate that the content of the symbolic self is likely to reflect both universality and uniqueness (Tooby \& Cosmides, 1990b). Attributes that have been relevant to our inclusive fitness in the past (e.g., evaluation of skills and abilities in relation to others, health condition, physical size, and strength) are likely to be universally reflected in the content of the symbolic self (Barkow, 1989). At the same time, in line with dialectic and anagenetic evolutionary accounts (Gariepy, 1995; Strube, Yost, \& Bailey, 1992; see also Hallowell, 1960), the content of the symbolic self is bound to contain idiosyncratic attributes. Such idiosyncratic attributes can either originate in the social system in which the individual currently lives (e.g., values, aspirations, and norms guiding personal and social conduct) or be the result of the individual's unique experiences (e.g., as shaped by time and place of birth, or by traveling).

These considerations suggest that research into the symbolic self can proceed fruitfully along multiple paths. Evolutionary origins, cross-cultural commonalities, and idiosyncrasies all are potentially informative routes of inquiry. We believe that all of these should be vigorously pursued.

\section{References}

Alexander, R. D. (1974). The evolution of social behavior. Annual Review of Ecology and Systematics, 5, 324-382.

Alexander, R. D. (1987). The biology of moral systems. New York: de Gruyter.

Alicke, M. D. (1985). Global selfevaluation as determined by the desirability and controllability of trait adjectives. Journal of Personality and Social Psychology, 49, 1621-1630.

Allport, G. W. (1943). The ego in contemporary psychology. Psychological Review, 50, 451-478.

Axelrod, R. (1984). The evolution of cooperation. New York: Basic Books.

Baldwin, J. D. (1986). Masters of social theory: Vol. 6. George Herbert Mead: A unifying theoryfor sociology. Newbury Park, CA: Sage.

Banaffi, M. R., \& Prentice, D. A. (1994). The self in social contexts. Annual Review of Psychology, 45, 297-332. 


\section{THE SYMBOLIC SELF}

Bargh, J. A. (1982). Attention and automaticity in the processing of selfrelevant information. Journal of Personality and Social Psychology, 43, 425-436.

Bargh, J. A. (1984). Automatic and conscious processing of social information. In R. S. Wyer, Jr. \& T. K. Srull (Eds.), Handbook of social cognition (Vol. 3, pp. 1-43). Hillsdale, NJ: Lawrence Erlbaum Associates, Inc.

Barkow, J. H. (1989). Darwin, sex, and status: Biological approaches to mind and culture. Toronto, Canada: University of Toronto Press.

Barkow, J. H. (1992). Beneath new culture is old psychology: Gossip and social stratification. In J. H. Barkow, L. Cosmides, \& J. Tooby (Eds.), The adapted mind: Evolutionary psychology and the generation of culture (pp. 627-637). New York: Oxford University Press.

Barkow, J. H., Cosmides, L., \& Tooby, J. (Eds.). (1992). The adapted mind: Evolutionary psychology and the generation of culture. New York: Oxford University Press

Baumeister, R. F. (1982). A selfpresentational view of social phenomena. Psychological Bulletin, 91, 3-26.

Baumeister, R. F. (1986). Public andprivate self. New York: Springer

Baurneister, R. F. (199 1). Escaping the self.. Alcoholism, spirituality, masochism, and otherflightsfrom the burden of sellhood. New York: Basic Books.

Baumeister, R. F, \& Leary, M. R. (1995). The need to belong: Desire for interpersonal attachments as a fundamental human motivation. Psychological Bulletin, 117, 497-529.

Baumeister, R. R, Smart, L., \& Boden, J. M. (1996). Relation of threatened egotism to violence and aggression: The dark side of high selfesteem. Psychological Review, 103, 5-33.

Baumeister, R. F, \& Tice, D. M. (1990). Anxiety and social exclusion. Journal of Social and Clinical Psychology, 9, 165-105.

Belk, R. W. (1988). Possessions and the extended self. Journal of Consumer Research, 15, 139-168.

Benedict, B. (1969). Role analysis in animals and men. Man, 4, 203-214.

Boccia, M. L. (1994). Mirror behavior in macaques. In S. T. Parker, R. W. Mitchell, \& M. L. Boccia (Eds.), Self-awareness in animals and humans (pp. 350-360). New York: Cambridge University Press.

Bower, G. H., \& Gilligan, S. G. (1979). Remembering information related to one's self. Journal of Research in Personality, 13, 420-432.

Bradley, G. W. (1978). Selfserving bias in the attribution process: A reexamination of the fact or fiction question. Journal of Personality and Social Psychology, 36, 56-7 1

Breckler, S. L, Pratkanis, A. R., \& McCann, C. D. (1991). The representation of self in multidimensional cognitive space. British Journal of Social Psychology, 30, 97-112.

Brewer, M. B. (1988). A dual process of impression formation. In T. K. Srull \& R. S. Wyer, Jr. (Eds.), Advances in social cognition (Vol. 1, pp. 1-36). Hillsdale, NJ: Lawrence Edbaum Associates, Inc.

Brewer, M. B., \& Caporael, L. R. (1990). Selfish genes versus selfish people: Sociobiology as origin myth. Motivation and Emotion, 14,237-243.

Breytspraak, L. M. (1984). The development of se r in later life. Boston: Little, Brown.

Brown, 3. D. (1993). Selfesteem and selfevaluation: Feeling is believing. In J. Suls (Ed.), Psychological perspectives on the seT (Vol. 4, pp. 27-58). Hillsdale, NJ: Lawrence Erlbaum Associates, Inc.

Brown, J. D., \& Dutton, K. A. (1995). Truth and consequences: The costs and benefits of accurate selfknowledge. Personality and Social Psychology Bulletin, 21, 1288-1296.

Burton, F. D. (1984). Inferences of cognitive abilities in Old World monkeys. Semiotica, 50, 69-81.

Buss, D. M. (1989). Sex differences in human mate preferences: Evolutionary hypotheses tested in 37 cultures. Behavioral and Brain Sciences, 12, 1-49.
Buss, D. M. (1990a). Evolutionary social psychology: Prospects and pitfalls. Motivation and Emotion, 14, 265-286.

Buss, D. M. (1990b). The evolution of anxiety and social exclusion. Journal of Social and Clinical Psychology, 9, 196-201.

Buss, D. M. (1991). Evolutionary personality psychology. Annual Review of Psychology, 45, 459-49 1.

Buss, D. M. (1994). The evolution of desire: Strategies of human mating. New York: Basic Books.

Buss, D. M. (1995). Evolutionary psychology: A new paradigm for psychological science. Psychological Inquiry, 6, 1-30.

Buss, D. M., Larsen, R. L, Westen, D., \& Semmelroth, J. (1992). Sex differences in jealousy: Evolution, physiology, and psychology. Psychological Science, 3, 251-255.

Buss, D. M., \& Schmitt, D. P. (1993). Sexual strategies theory: An evolutionary perspective on human mating. Psychological Review, 100, 204-232.

Byrne, R. W., \& Whiten, A. (Eds.). (1988). Machiavellian intelligence: Social expertise and the evolution of intellect in monkeys, apes, and humans. Oxford, England: Clarendon.

Campbell, D. T. (1975). On the conflicts between biological and social evolution and between psychology and moral tradition. American Psychologist, 30, 1103-1126.

Cantor, N., Mackie, D. M., \& Lord, C. G. (1984). Choosing partners and activities: The social perceiver decides to mix it up. Social Cognition, 3, 256-272.

Cantor, N., Markus, H., Niedenthal, P., \& Nurius, P. (1986). On motivation and the selfconcept. In R. M. Sorrentino \& E. T. Higgins (Eds.), Motivation and cognition: Foundations ofsocial behavior (pp. 96-127). New York: Guilford.

Caporael, L. R., \& Brewer, M. B. (1991). Reviving evolutionary psychology: Biology meets society. Journal ofSocial Issues, 47, 187-195.

Cavalli-Sforza, L. L., \& Feldman, M. W. (1981). Cultural transmission and evolution: A quantitative approach. Princeton, NJ: Princeton University Press.

Chan, L. K. W. (1992). Problems with socioecological explanations of primate social diversity. In F. D. Button (Ed.), Social processes and mental abilities in non-human primates (pp. 1-30). Lewiston, NY Edwin Mellen Press.

Cheney, D. L., \& Seyfarth, R. M. (1992). Pr6cis of how monkeys see the world. Behavioral and Brain Sciences, 15, 135-182.

Chomsky, N. (1972). Language and mind. New York: Harcourt Brace.

Clutton-Brock, T. H., \& Harvey, P. H. (1977). Primate ecology and social organization. Journal of Zoology, 183, 1-39.

Cosmides, L. (1989). The logic of social exchange: Has natural selection shaped how humans reason? Cognition, 31, 187-276.

Cosmides, L., \& Tooby, J. (1989). Evolutionary psychology and the generation of culture, Part 11. Case study: A computational theory of social exchange. Ethology and Sociobiology, 10, 51-98.

Crook, J. H., Ellis, J. E., \& Goss-Custard, J. D. (1976). Mammalian social system: Structure and function. Animal Behavior, 24 261-274.

Crook, J. H., \& Gartlan, J. S. (1966). Evolution of primate societies. Nature, 210, 1200-1203.

Cupach, W. R., \& Metts, S. (1994). Facework- Thousand Oaks, CA: Sage.

Damasio, A. R. (1994). Descartes' error: Emotion, reason and the human brain. New York: Putnam.

Damon, W. (1983). Social and personality development: Infancy through adolescence. New York: Norton.

Damon, W., \& Hart, D. (1986). Stability and change in children's selfunderstanding. Social Cognition, 4, 102-118.

Darwin, C. (1859). On the origin of the species by means of natural selection, or, the preservation offavored races in the struggle for life. London: John Murray.

Darwin, C. (187 1). The descent of man, and selection in relation to sex. New York: Appleton. 


\section{SEDIKIDES \& SKOWRONSKI}

Day, M. H. (1986). Guide to fossil man. Chicago: University of Chicago Press

DeKay, W. T., \& Buss, D. M. (1992). Hurnan nature, individual differences, and the importance of context: Perspectives from evolutionary psychology. Current Directions in Psychological Science, 1, 184-189.

Deutsch, F. M., Ruble, D. N., Fleming, A., Brooks-Gunn, J., \& Stangor, C. (1988). Information-seeking and maternal self-deflnition during the transition to motherhood. Journal of Personality and Social Psychology, 55, 420-431.

de WaaL F. B. M. (1982). Chimpanzee politics. New York Harper \& Row.

de Waal, F. B. M. (1986). Deception in the natural communication of chimpanzees. In R. W. Mitchell \& N. S. Thompson (Eds.), Deception: Perspectives on human and nonhuman deceit (pp. 221-266). Albany, NY: State University of New York Press.

Dobzhansky, T. (1964). Heredity and the nature of man. New York: New American Library.

Dunning, D. (1993). Words to live by: The self and definitions of social concepts and categories. In J. Suls (Ed.), Psychological perspectives on the self (Vol. 4, pp. 99-126). Hillsdale, NJ: Lawrence ErIbaum Associates, Inc.

Duval, S., \& Wicklund, R. A. (1972). A theory of objective self awareness. New York: Academic.

Eglash, A. R., \& Snowdon, C. T. (1983). Miffor-image responses in pygmy marmosets (Cebuella pygmaea). American Journal of Primatology, 5, 211-219.

Eisenberg, J. E, Muchenhim, N. A., \& Rudran, R. (1972). The relation between ecology and social structure in primates. Science, 176, 863-874.

Elias, H., \& Bortner, S. (1957). On the phylogeny of hair American Museum Novitates, 1820, 1 -15.

Ellis, B. L, \& Symons, D. (1990). Sex differences in sexual fantasy: An evolutionary psychological approach. Journal of Sex Research, 27, 527-556.

Falk, D. (1987). Hominid paleoneurology. Annual Review ofAnthropology, 16, 13-30.

Fiske, S. T., \& Neuberg, S. L. (1990). A continuum of impression formation, from category-based to individuating processes: Influences of information and motivation on attention and interpretation. In M. P. Zanna (Ed.), Advances in experimental social psychology (Vol. 23, pp. 1-74). New York: Academic.

Fodor, J. A., Bever, T. G., \& Garrett, M. F. (1974). The psychology of language. New York: McGraw-Hill.

Fox, M. W. (1982). Are most animals "mindless automatons'T A reply to Gordon G. Gallup, Jr. American Journal of Primatology,3,341-343.

Fox, R. (1980). The red lamp of incest. New York: Dutton.

Fox, R. (1992). Prejudice and the unfinished mind: A new look at an old failing. Psychological Inquiry, 3, 137-152.

Galdikas, B. F., \& Vasey, P. (1992). Why are orangutans so srnart? Ecological and social hypotheses. In F. D. Burton (Ed.), Social processes and mental abilities in non-human primates: Evidence from longitudinalfield studies ( $p p$. 183-224). Lewiston, NY: Edwin Mellen Press.

Gallistel, C. R. (1989). Animal cognition. Annual Review of Psychology, 40, 155-189.

Gallup, G. G., Jr. (1970). Chimpanzees: Self-recognition Science, 167,86-87.

Gallup, G. G.,Jr. (1977). Self-recognition in primates: A comparative approach to the bidirectional properties of consciousness. American Psychologist, 32, 329-338.

Gallup, G. G., Jr. (1983). Toward a comparative psychology of mind. In R. E. Mellgren (Ed.), Animal cognition and behavior (pp. 473-510). Amsterdam: North-Holland.

Gallup, G. G., Jr. (1985). Do n-dnds exist in species other than our own? Neuroscience and Biobehavioral Reviews, 9, $631-641$

Gallup, G. G., Jr. (1992). Levels, limits, and precursors to self-recognition: Does ontogeny recapitulate phylogeny? Psychological Inquiry, 3, 117-118.
Gallup, G. G., Jr. (1994). Monkeys, mirrors, and minds. Behavioral and Brain Sciences, 17, 572-573.

Gallup, G. G., Jr., \& Suarez, S. D. (1986). Self-awareness and the emergence of mind in humans and other primates. In J. Suls \& A. G. Greenwald (Eds.), Psychological perspectives on the self (Vol. 3, pp. 326). Hillsdale, NJ: Lawrence ErIbaurn Associates, Inc.

Gangestad, S. W., \& Simpson, J. A. (1990). Toward an evolutionary history of female sociosexual variation. Journal of Personality, 58,69-96.

Gaidepy, J.-I_. (1995). The making of a developmental science: Historical trends in animal behavior research. In R. Vasta (Ed.), Annals of child development (Vol. 10, pp. 167-222). London, PA: Jessica Kingsley.

Ghiglieri, M. P. (1989). Hominoid sociobiology and hominid social evolution. In P. G. Heltne \& L. A. Marquardt (Eds.), Understanding chimpanzees (pp. 370-379). Cambridge, MA: Harvard University Press

Gibson, K. R. (1986). Cognition, brain size, and the extraction of embedded food resources. In J. G. Else \& P. C. Lee (Eds.), Primate ontogeny, cognition and social behavior (pp. 93-103). Cambridge, England: Cambridge University Press.

Goodall, J. (1986). The chimpanzees of Gombe. Cambridge, MA Haryard University Press.

Gould, S. J. (1982). Darwinism and the expansion of evolutionary theory. Science, 216, 380-387.

Gould, S. J. (1985). The flamingo's smile: Reflections in natural history. New York: Norton.

Greenwald, A. G., \& Banaffi, M. R. (1989). The self as a memory system: Powerful but ordinary. Journal of Personality and Social Psychology, 57, 41-54.

Gregory, W. L., Cialdini, R. B., \& Carpenter, K. M. (1982) Self-relevant scenarios as mediators of likelihood estimates and compliance: Does imagining make it so? Journal of Personality and Social Psychology, 43, 89-99,

Griffin, D. R. (1976). The question of animal awareness. New York: Rockefeller University Press.

Guisinger, S., \& Blatt, S. J. (1994). Individuality and relatedness: Evolution of fundamental dialectic. American Psychologist, 49, 104-111

Gur, C. R., \& Sackheim, H. A. (1979). Self-deception: A concep in search of a phenomenon. Journal of Personality and Social Psychology, 37, 147-169.

Hallowell, A. 1. (1960). Self, society, and culture in phylogenetic perspective. In S. Tax (Ed.), Evolution after Darwin (Vol. 2, pp 309-371). Chicago: University of Chicago Press.

Hamilton, W. D. (1964). The genetic evolution of social behavior, Parts I and Il. Journal of Theoretical Biology, 7, $1-52$.

Harcourt, A. H. (1988). Alliances in contest and social intelligence. In R. Byrne \& A. Whiten (Eds.), Machiavellian intelligence: Social expertise and the evolution of intellect in monkeys, apes and humans (pp. 132-152). Oxford, England: Oxford University Press.

Hattiangadi, J. N. (1973). Mind and the origin of language. Philosophical Forum, 14, 81-98.

Hermans, H. J. M. (1996). Voicing the self.. From information processing to dialogical interchange. Psychological Bulletin, $119,31-50$.

Higgins, E. T. (1987). Self-disempancy: A theory relating self to affect. Psychological Review, 94, 319-340.

Hinde, R. A., \& Stevensen-Hinde, J. (1976). Towards understanding relationships: Dynamic stability. In P. P. G. Bateson \& R. A. Hinde (Eds.), Growing points in ethology (pp. 451-480). Cambridge, England: Cambridge University Press

Hodos, R. J. (1986). The evolution of the brain and the nature of animal intelligence. In R. J. Hoage \& L. Goldman (Eds.), Animal 
intelligence: Insights into the animal mind (pp. 77-87), Washington, DC: Smithsonian Institution Press.

Holloway, R. L. (1975). Early hominid endocasts. In R. H. Turtle (Ed.), Primate functional morphology and evolution (pp. 393-415). The Hague, The Netherlands: Mouton.

Huxley, J. S. (1938). The present standing of the theory of sexual selection. In G. R. de Beer (Ed.), Evolution: Essays on aspects of evolutionary biology presented to Professor E. S. Goodrich on hisseventieth birthday (pp. 11-42). Oxford, England: Clarendon.

Huxley, J. S. (1957). The three types of evolutionary progress. Nature, $180,454-455$.

Hyatt, C. W., \& Hopkins, W. D. (1994). Selfawareness in bonobos and chimpanzees: A comparative perspective. In S. T. Parker, R. W. Mitchell, \& M. L. Boccia, (Eds.), Self-awareness in animals and humans: Developmental perspectives (pp. 248-253). New York: Cambridge University Press.

Isaac, G. (1978). The food-sharing behavior of proto-human hominids. Scientific American, 238, 90-108.

James, W. (1898). The will to believe.. And other essays in popular philosophy. London: Longmans, Green.

James, W. (1950). The principles of psychology. New York: Dover. (Original work published 1890)

Jaynes, J. (1976). The origin of consciousness in the break-down of the bicameral mind. Boston: Houghton Mifflin.

Kahle, L. R., Kulka, R. A., \& Klingel, D. M. (1980). Low adolescent selfesteem leads to multiple interpersonal problems: A test of social adaptation theory. Journal of Personality and Social Psychology, 39, 496-502.

Kaplan, H. B. (1975). Seffiattitudes and deviant behavior. Pacific Palisades, CA: Goodyear.

Kaplan, S. (1976). Adaptation, structure, and knowledge. In G. T. Moore \& R. G. Golledge (Eds.), Environmental knowing: Theories, research, and methods (pp. 32-45). Stroudsberg, PA: Dowden, Hutchinson \& Ross.

Kaplan, S. (1992). Environmental preference in a knowledge-seeking, knowledge-using organism. In J. H. Barkow, L. Cosmides, \& J. Tooby (Eds.), The adapted mind: Evolutionary psychology and the generation of culture (pp. 581-598). New York: Oxford University Press.

Kaplan, S., \& Kaplan, R. (1978). Humanscape. North Scituate, MA: Duxbury.

Kenny, D. A., \& DePaulo, B. M. (1993). Do people know how others view them? An empirical and theoretical account. Psychological Bulletin, 114, 145-161.

Kenrick, D. T. (1994). Evolutionary social psychology: From sexual selection to social cognition. In M. P. Zanna (Ed.), Advances in experimental social psychology (Vol. 26, pp. 75-121). New York: Academic.

Kenrick, D. T., Groth, G., Trost, M. R., \& Sadalla, E. K. (1993). Integrating evolutionary and social exchange perspectives on relationships: Effects of gender, selfappraisal, and involvement level on mate selection. Journal of Personality and Social Psychology, 64, 951-969.

Kenrick, D. T., \& Keefe, R. C. (1992). Age preferences in mates reflect sex differences in human reproductive strategies. Behavioral and Brain Sciences, 15, 75-133.

Klein, R. G. (1992). The archeology of modem human origins. Evolutionary Anthropology, 1, 5-14.

Kraut, R. E. (1973). Effects of social labeling on giving to charity. Journal of Experimental Social Psychology, 9, 551-562.

Kuiper, N. A. (198 1). Convergent evidence for the self as prototype: The \%nverted-U RT effecC for self and other judgments. Personality and Social Psychology Bulletin, 7, 438-443.

Kummer, H. (197 1). Primate societies: Group techniques of ecological adaptation. Chicago: Aldine.

Kunda, Z. (1990). The case for motivated reasoning. Psychological Bulletin, 108, 480-498.
Laughlin, W. S. (1966). Hunting: An integrating biobehavior system and its evolutionary importance. In R. B. Lee \& I. DeVore (Eds.), Man the hunter (pp. 304-320). Chicago: Aldine.

Leakey, L. (1966). Homo habilis, Homo erectus, and the australopithecines. Nature, 209, 1279-1281.

Leary, M. R. (1995). Self-presentation: Impression management and interpersonal behavior. Madison, WI: Brown \& Benchmark.

Leary, M. R., Tambor, E. S., Terdal, S. K., \& Downs, D. L. (1995). Selfesteem as an interpersonal monitor: The sociometer hypothesis Journal of Personality and Social Psychology, 68, 518-530.

Ledbetter, D. H., \& Basen, J. D. (1982). Failure to demonstrate selfrecognition in gorillas. American Journal of Primatology, 2,307-310.

LeDoux, J. (1989). Cognitive and emotional interactions in the brain Cognition and Emotion, 3, 265-289.

Lewis, M. (1990). Selfknowledge and social development in early life. In L. A. Pervin (Ed.), Handbook ofpersonality: Theory and research (pp. 277-300). New York: Guilford.

Lewis, M. (1992). Will the real self or selves please stand up? Psychological Inquiry, 3, 123-124.

Linville, P. W. (1987). Selfcomplexity as a cognitive buffer against stress-related illness and depression. Journal of Personality and Social Psychology, 52, 663-676.

Lorenz, K. (1963). On aggression. New York: Harcourt.

Mandler, G. (1975). Mind and emotion. New York: Wiley.

Marino, L., Reiss, D., \& Gallup, G. G., Jr. (1994). Mirror selfrecognition in bottlenose dolphins: Implications for comparative investigations of highly dissimilar species. In S. T. Parker, R. W. Mitchell, \& M. L. Boccia (Eds.), Seff-awareness in animals and humans: Developmental perspectives (pp. 380-391). New York: Cambridge University Press.

Markus, H. (1977). Self-schemata and processing information about the self. Journal of Personality and Social Psychology, 35, 63-78.

Markus, H. (1983). Selfknowledge: An expanded view. Journal of Personality, 51, 543-565.

Markus, H. R., \& Kitayama, S. (1991). Culture and the self: Implication for cognition, emotion, and motivation. Psychological Review, 98,224-253.

Markus, H., \& Nurius, P. (1986). Possible selves. American Psychologist, 41, 954-969.

Markus, H., Sn-iith, J., \& Moreland, R. L. (1985). Role of the self concept in the perception of others. Journal of Personality and Social Psychology, 49, 1494-1512.

Markus, H., \& Wurf, E. (1987). The dynamic selfconcept: A social psychological perspective. Annual Review of Psychology, 38, 299-337.

Marten, K., \& Psarakos, S. (1994). Evidence of selfawareness in the bottlenose dolphin (Tursiops truncatus). In S. T. Parker, R. W. Mitchell, \& M. L. Boccia (Eds.), Self-awareness in animals and humans: Developmental perspectives (pp. 361-379). New York: Cambridge University Press.

Maryanski, A., \& Turner, J. H. (1992). The social cage: Human nature and the evolution of society. Stanford, CA: Stanford University Press.

MeGrew, W. C., \& Feistner, A. T. C. (1992). Two nonhuman primate models for the evolution of human food sharing: Chimpanzees and callitrichids. In J. Barkow, L. Cosmides, \& J. Tooby (Eds.), The adapted mind (pp. 229-243). New York: Oxford University Press.

MeGuire, W. L, MeGuire, C. V., \& Cheever, J. (1986). The self in society: Effects of social contexts on the sense of self. British Journal of Social Psychology, 25, 259-270.

McHenry, H. M. (1992). How big were early hominids? Evolutionary Anthropology, 1, 15-19.

Meichenbaum, D. (1977). Cognitive-behavioral modification: An integrative approach. New York: Plenum. 


\section{SEDIKIDES \& SKOWRONSKI}

Menzel, E. W. (1971). Communication about the environment in a group of young chimpanzees. Folia Primatologia, 15, 220-232.

Menzel, E. W. (1978). Cognitive mapping in chimpanzees. In S. H. Hulse, H. Fowler, \& W. K. Honig (Eds.), Cognitive process in animal behavior (pp. 375-422). Hillsdale, NJ: Lawrence Erlbaum Associates, Inc.

Miles, H. L. W. (1994). Me Chantek: The development of selfawareness in a singing orangutan. In S. T. Parker, R. W. Mitchell, \& M. L. Boccia (Eds.), Self-awareness in animals and humans: Developmental perspectives (pp. 254-272). New York: Cambridge University Press.

Miller, R. L., Brickman, P., \& Bolen, D. (1975). Attribution versus persuasion as a means of modifying behavior. Journal of Personality and Social Psychology, 31, 430-44 1.

Milton, K. (198 1). Distribution patterns of tropical plant foods as an evolutionary stimulus to primate mental development. American Anthropologist, 83, 534-548.

Milton, K. (1988). Foraging behaviour and the evolution of primate intelligence. In R. Byrne \& A. Whiten (Eds.), Machiavellian intelligence: Social expertise and the evolution of intellect in monkeys, apes and humans (pp. 285-305). Oxford, England: Oxford University Press

Mitchell, R. W. (1993). Mental models of mirror selfrecognition: Two theories. New Ideas in Psychology, 11, 295-325.

Mitchell, R. W. (1994). Multiplicities of self. In S. T. Parker, R. W. Mitchell, \& M. L. Boccia (Eds.), Self-awareness in animals and humans: Developmental perspectives (pp. 81-107). New York: Cambridge University Press.

Mitchell, R. W., \& Thompson, N. S. (Eds.). (1986). Deception: Perspectives on human and nonhuman deceit. Albany, NY: State University of New York Press.

Monge, R. H. (1975). Structure of the selfconcept from adolescence through old age. Experimental Aging Research, 1, 281-291.

Mortimer, J. T., \& Lorence, J. (1981). Selfconcept, stability and change from late adolescence to early adulthood. Research in Community Mental Health, 2, 5-42.

Nesse, R. M. (1990). The evolution of repression and the ego defenses. Journal of the American Academy ofPsychoanalysis, 18, 260-286.

Nesse, R. M., \& Lloyd, A. T. (1992). The evolution of psychodynamic mechanisms. In J. H. Barkow, L. Cosmides, \& J. Tooby (Eds.), The adapted mind: Evolutionary psychology and the generation ofculture (pp. 601-624). New York: Oxford University Press.

Ofiver, M. B., \& Sedikides, C. (1992). Effects of sexual permissiveness on desirability of partner as a function of low and high commitment to relationship. Social Psychology Quarterly, 55, 321-333.

Ostrom, T. M_ Pryor, J. B., \& Simpson, D. D. (1981). The organization of social information. In E. T. Higgins, C. P. Herman, \& M. P. Zanna (Eds.), Social cognition: The Ontario Symposium (pp. 3-38) Hillsdale, NJ: Lawrence Erlbaum Associates, Inc.

Oyserman, D., \& Markus, H. R. (1990). Possible selves and delinquency. Journal of Personality and Social Psychology, 59, 112-125.

Parker, S. T. (1987). A sexual selection model for hominid evolution. Human Evolution, 2, 235-253.

Parker, S. T., \& Gibson, K. R. (1979). A developmental model for the evolution of language and intelligence in early hominids. Brain and Behaviour Science, 2, 367-408.

Patterson, F, \& Linden, E. (198 1). The education ofKoko. New York: Holt, Rinchart \& Winston.

Peters, R., \& Mech, L. D. (1975). Behavioral and intellectual adaptations of selected mammalian predators to the problem of hunting large animals. In R. H. Tuttle (Ed.), Socioecology and psychology ofprimates (pp. 279-300). Chicago: Aldine.
Povinelli, D. J. (1993). Reconstructing the evolution of mind. American Psychologist, 48, 493-509.

Povinelli, D. J. (1994). A theory of nffind is in the head, not the heart. Behavioral and Brain Sciences, 17, 573-574

Povinelli, D. L, Nelson, K. E., \& Boysen, S. T. (1992a). Comprehension of social role reversal by chimpanzees: Evidence of empathy? Animal Behaviour, 43, 633-640.

Povinelli, D. L, Nelson, K. E., \& Boysen, S. T. (1992b). Inferences about guessing and knowing by chimpanzees (Pan troglodytes). Journal of Comparative Psychology, 104, 203-2 10.

Povinelli, D. L, Parks, K. A., \& Novak, M. A. (1992). Role reversal by rhesus monkeys, but no evidence of empathy. Animal Behaviour, 44, 269-281

Povinelli, D. 1, Rulf, A. B., \& Bierschwale, D. (1993). Absence of knowledge attribution and selfrecognition in young chimpanzees (Pan troglodytes). Journal of Comparative Psychology, 107,347-372.

Premack, D., \& Premack, A. G. (1983). The mind of an ape. New York: Norton.

Premack, D., \& Woodruff, G. (1978). Does the chimpanzee have a theory of rnind? Behavior and Brain Sciences, 1, 515-526.

Rensch, B. (1959). Evolution above the species level. London: Methuen.

Ristau, C. A. (Ed.). (1991). Cognitive ethology.. The minds of other animals. Hillsdale, NJ: Lawrence Erlbaum Associates, Inc.

Rodseth, L., Wrangham, R. W., Harrigan, A., \& Smuts, B. B. (1991). The human community as aprimate society. Current Anthropology,32,221-254.

Rogers, T. B., Kuiper, N. A., \& Kirker, W. S. (1977). Selfreference and the encoding of personal information. Journal of Personality and Social Psychology, 35, 677-688.

Rosenberg, M. (1988). Selfobjectification: Relevance for the species and society. Sociological Forum, 3, 548-565.

Rtivolo, A. P., \& Markus, H. R. (1992). Possible selves and performance: The power of selfrelevant imagery. Social Cognition, 10, 95-124.

Sackheim, H. A. (1983). Selfdeception, selfesteem, and depression: The adaptive value of lying to oneself. In J. Masling (Ed.), Empirical studies of psychoanalytic theories (Vol. 1, pp. 101 -157). London: The Analytic Press.

Savage-Rumbaugh, E. S. (1986). Ape language: From conditioned response to symbol. New York: Columbia University Press.

Savage-Rumbaugh, E. S., \& McDonald, K. (1988). Deception and social manipulation in symbol-using apes. In R. W. Byrne \& A. Whiten (Eds.), Machiavellian intelligence (pp. 224-237). Oxford, England: Oxford University Press.

Sawaguchi, T. (1990). Relative brain size, stratification, and social structure in anthropoids. Primates, 31, 257-272.

Schlenker, B. R. (1980). Impression management. Monterey, CA: Brooks/Cole

Schmidt-Atzert, L. (1988). Affect and cognition: On the chronological order of stimulus evaluation and emotion. In K. Fiedler \& J. Forgas (Eds.), Affect, cognition, and social behavior: New eidence and integrative attempts (pp. 153-164). Toronto: Hogrefe.

Sedikides, C. (1993). Assessment, enhancement, and verification determinants of the selfevaluation process. Journal of Personality and Social Psychology, 65, 317-338.

Sedikides, C., \& Skowronski, J. J. (1993). The self in impression formation: Trait centrality and social perception. Journal of Experimental Social Psychology, 29, 347-357.

Sedikides, C., \& Skowronski, J. J. (1995). Sources of selfknowledge: On the perceived primacy of selfreflection. Journal of Social and Clinical Psychology, 14, 244-270.

Sedikides, C., \& Strube, M. J. (in press). Selfevaluation: To thine own self be good, to thine own self be sure, to thine own self be true, and to thine own self be better. In M. P. Zanna (Ed.), 
Advances in Experimental Social Psychology. New York: Academic.

Seyfarth, R., \& Cheney, D. (1989). How monkeys see the world. Chicago: University of Chicago Press.

Shettleworth, S. J. (1993). Where is the comparison in comparative cognition? Psychological Science, 4, 179-184.

Shotland, R. L., \& Berger, W. G. (1970). Behavioral validation of several values from the Rokeach Value Scale as an index of honesty. Journal of Applied Psychology, 54, 433-435.

Sibley, C. G., \& Ahlquist, J. E. (1984). The phylogeny of the hon-dnoid primates, as indicated by DNA-RNA hybridization. Journal of Molecular Evolution, 20, 2-15.

Silverman, I., \& Eals, M. (1992). Sex differences in spatial abilities: Evolutionary theory and data. In J. Barkow, L. Cosmides, \& J. Tooby (Eds.), The adapted mind (pp. 533-549). New York: Oxford University Press.

Simon, H. A. (1990). A mechanism for social selection and successful altruism. Science, 250, 1665-1668.

Skowronski, J. J., Betz, A. L., Thompson, C. P., \& Shannon, L. (199 1). Social memory in everyday life: The recall of selfevents and other-events. Journal ofPersonality and Social Psychology, 60,831-843.

S muts, B. B. (199 1). Male aggression against women: An evolutionary perspective. Human Nature, 3, 1-44.

Snowdon, C. T. (1991). Language capacities in nonhuman animals. Yearbook af Physical Anthropology, 33, 215-243.

Snyder, M., Gangestad, S., \& Simpson, J. A. (1983). Choosingfriends; as activity partners: The role of selfmonitoring. Journal of Personality and Social Psychology, 45, 1061-1072.

Solomon, S., Greenberg, L, \& Pyszczyriski, T. (1991). A terror management theory of social behavior: The psychological functions of selfesteem and cultural worldviews. In M. P. Zanna (Ed.), Advances in experimental social psychology (Vol. 24, pp. 93-159). San Diego, CA: Academic.

Staats, S., \& Skowronski, J. J. (1992). Perceptions of selfaffect: Now and in the future. Social Cognition, 10, 415-43 1 .

Strube, M. L, Yost, J. H., \& Bailey, J. R. (1992). William James and contemporary research on the self: The influence of pragmatism, reality, and truth. In M. E. Donnelley (Ed.), Reinterpreting the legacy $q f^{*}$ William James (pp. 189-207). Washington, DC: American Psychological Association.

Stryker, S., \& Statham, A. (1985). Symbolic interaction and role theory. In G. Lindzey \& E. Aronson (Eds.), Handbook qf social psychology (Vol. II, pp. 311-378). New York: Random House.

Stuss, D. T. (1991). Selfawareness, and the frontal lobes: A neuropsychological perspective. h J. Strauss \& G. R. Goethals (Eds.), The self.. Interdisciplinary approaches (pp. 255-278). New York: Springer-Verlag.

Suarez, S. D_ \& Gallup, G. G., Jr. (1981). Selfrecognition in chimpanzees and orangutans, but not gorillas. Journal of Human Evolution, 10, 175-188.

Swann, W. B. (1990). To be adored or to be known? The interplay of selfenhancement and selfverification. In E. T. Higgins \& R. M. Sorrentino (Eds.), Handbook ol motivation and cognition: Foundations q/ social behavior (Vol. 2, pp. 408-448). New York: Guilford.

Swartz, K., \& Evans, S. (1994). Social and cognitive factors in chimpanzee and gorilla mirror behavior and selfrecognition. In S. T Parker, R. W. Mitchell, \& M. L. Boccia (Eds.), Self-awareness in animals and humans (pp. 189-206). New York: Cambridge University Press.

Symons, D. (1992). On the use and misuse of Darwinism in the study of human behavior. In J. H. Barkow, L. Cosmides, \& J. Tooby (Eds.), The adapted mind.. Evolutionary psychology and the generation of culture (pp. 137-159). New York: Oxford University Press.

Taylor, S. E_ \& Brown, J. D. (1988). Illusion and well-being: A social psychological perspective on mental health. Psychological Bulletin, 103, 193-210.

Tesser, A. (1988). Toward a selfevaluation maintenance model of social behavior. In L. Berkowitz (Ed.), Advances in experimental social psychology (Vol. 2 1, pp. 181-227). San Diego, CA: Academic.

Tice, D. M. (1992). Selfconcept change and selfpresentation: The looking glass self is also a magnifying glass. Journal oj'Personality and Social Psychology, 63, 435-45 1.

Tobias, P. V. (1971). The brain in hominid evolution. New York: Columbia University Press.

Tooby, L, \& Cosmides, L. (1 990a). Evolutionary psychologists need to distinguish between the evolutionary process, ancestral selection pressures, and psychological mechanisms. Behavioral and Brain Sciences, 12, 724-725.

Tooby, L, \& Cosmides, L. (1990b). On the universality of human nature and the uniqueness of the individual: The role of genetics and adaptation. Journal of Personality, 58, 17-67.

Tooby, 1, \& Cosmides, L. (1992). The psychological foundations of culture. In J. H. Barkow, L. Cosmides, \& J. Tooby (Eds.), The adapted mind: Evolutionary psychology and the generation of culture (pp. 19-136). New York: Oxford University Press.

Triandis, H. C. (1989). The self and social behavior in differing cultural contexts. Psychological Review, 96, 506-520.

Trivets, R. L. (197 1). The evolution of reciprocal altruism. Quarterly Review (?f Biology, 46, 35-57.

Trivets, R. (1985). Social evolution. Menlo Park, CA: Benjamin Cummings.

Van Schaik, C. (1983). Why are diurnal primates living in groups? Behavior, 87, 120-144.

Vine, 1. (1987). Inclusive fitness and the selfsystem: The roles of human nature and sociocultural processes in intergroup discrimination. In V. Reynolds, V. Falger, \& I. Vine (Eds.), The sociobiology pf ethnocentrism: Evolutionary dimensions of xenophobia, discrimination, racism and nationalism (pp. 60-80). London: Croom Helm.

Visalberghi, E., \& Trinea, L. (1989). Tool use in capuchin monkeys: Distinguishing between performing and understanding. Primates, 30, 511-521.

Von Bertalanffy, L. (1967). Robots, men and minds. New York. Braziller.

Wallace, R. (1989). Cognitive mapping and the origin of language and mind. Current Anthropology, 30, 518-526.

Weiskrantz, L. (1986). Blindsight: A case study and implications. Oxford, England: Oxford University Press.

Whiten, A., \& Byrrie, R. W. (1988). Tactical deception in primates. Behavioral and Brain Sciences, 11, 233-273.

Whitley, B. E. (1983). Sex role orientation and selfesteem: A critical meta-analytic review. Journal of' Personality and Social Psychology, 44, 765-778.

Wicklund, R. A. (1975). Objective selfawareness. In L. Berkowitz (Ed.), Advances in experimental social psychology (Vol. 8, pp. 233-275). New York: Academic.

Wicklund, R. A_\& Gollwitzer, P. M. (1982). Symbolic selfcompletion. Hillsdale, NJ: Lawrence Erlbaum Associates, Inc.

Wills, T. A. (1981). Downward comparison principles in social psychology. Psychological Bulletin, 90, 245-27 1.

Wilson, D. S., \& Sober, E. (1994). Reintroducing group selection to the human behavioral sciences. Behavioral and Brain Sciences, $17,585-654$

Wilson, E. 0. (1975). Sociobiology: The new synthesis. Cambridge, MA: Harvard University Press.

Wilson, T. D., Dunn, D. S., Kraft, D., \& Lisle, D. J. (1989). Introspection, attitude change, and attitude-behavior consistency: The disruptive effects of explaining why we feel the way we do. In L. Berkowitz (Ed.), Advances in experimental 
SEDIKIDES \& SKOWRONSKI

social psychology (Vol. 22, pp. 287-343). San Diego, CA: Academic.

Wrangham, R. W. (1979). On the evolution of ape social systems.

Social Science Information, 18, 334-368.

Yunis, J. J., \& Prakash, 0. (1982). The origin of man: A chromosomal pictorial legacy. Science, 215, 1525-1530.
ZaJonc, R. B. (1980). Feeling and thinking: Preferences need no inferences. American Psychologist, 35, 151-175.

Zeller, A. (1992). Communication in the social unit. In F. D. Button (Ed.), Social processes and mental abilities in non-human primates: Evidences. Irom longitudinalfield studies (pp. 61-89). Lewiston, NY: Edwin Mellen Press. 